\title{
Which children and young people are at higher risk of severe disease and death after SARS-CoV-2 infection: a systematic review and individual patient meta-analysis
}

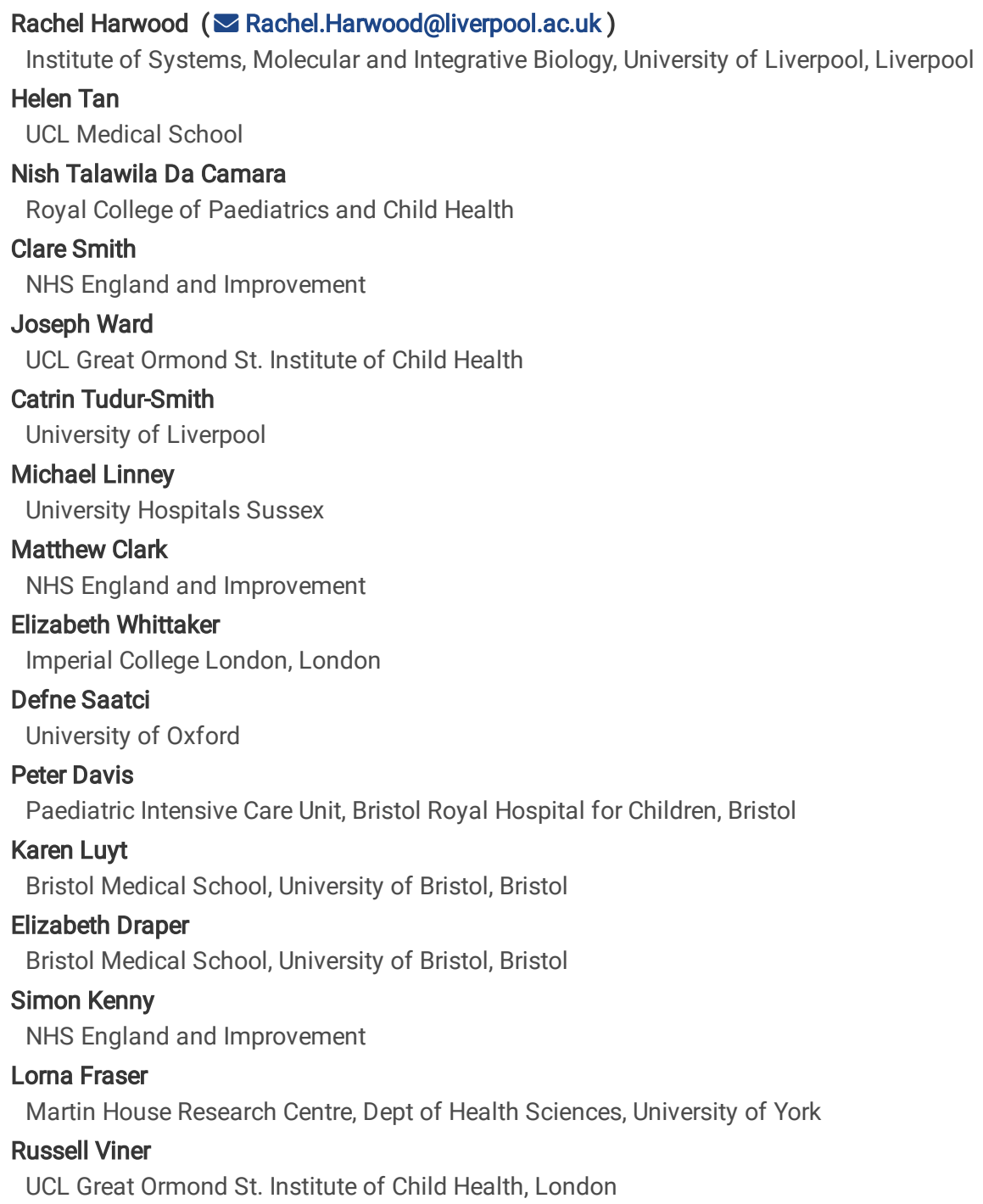




\section{Abstract}

Background We aimed to use individual patient data to describe pre-existing factors associated with severe disease, primarily admission to critical care, and death secondary to SARS-CoV-2 infection in children and young people (CYP) in hospital.

Methods We searched Pubmed, European PMC, Medline and Embase for case series and cohort studies that included all CYP admitted to hospital with 30 CYP with SARS-CoV-2 or 5 CYP with PIMS-TS or MIS-C. Eligible studies contained 1) details of age, sex, ethnicity or co-morbidities, and 2) an outcome which included admission to critical care, mechanical invasive ventilation, cardiovascular support, or death. Studies reporting outcomes in more restricted grouping of co-morbidities were eligible for narrative review. Authors of eligible studies were approached for individual patient data (IPD). We used random effects meta-analyses for aggregate study-level data and multilevel mixed effect models for IPD data to examine risk factors (age, sex, comorbidities) associated with admission to critical care and death. Data shown are odds ratios and $95 \%$ confidence intervals (Cl).

Findings 81 studies were included, 57 in the meta-analysis (of which 22 provided IPD) and 26 in the narrative synthesis. Most studies had an element of bias in their design or reporting. Sex was not associated with critical care or death. Compared with CYP aged 1-4 years, infants had increased odds of admission to critical care (OR 1.63 (95\% Cl 1.40-1.90)) and death (OR 2.08 (1.57-2.86)). Odds of death were increased amongst CYP over 10 years (1014 years OR $2.15(1.54-2.98) ;>14$ years OR $2.15(1.61-2.88))$.

Number of comorbid conditions was associated with increased odds of admission to critical care and death for COVID-19 in a dose-related fashion. For critical care admission odds ratios were: 1 comorbidity 1.49 (1.45-1.53); 2 comorbidities 2.58 (2.41-2.75); $\geq 3$ comorbidities 2.97 (2.04-4.32), and for death: 1 comorbidity 2.15 (1.98-2.34); 2 comorbidities 4.63 (4.54-4.74); $\geq 3$ co-morbidities 4.98 (3.78-6.65). Odds of admission to critical care were increased for all co-morbidities apart from asthma (0.92 (0.91-0.94)) and malignancy $(0.85(0.17-4.21))$ with an increased odds of death in all comorbidities considered apart from asthma. Neurological and cardiac comorbidities were associated with the greatest increase in odds of severe disease or death. Obesity increased the odds of severe disease and death independently of other comorbidities.

Interpretation Hospitalised CYP at greatest vulnerability of severe disease or death from SARS-CoV-2 infection are infants, teenagers, those with cardiac or neurological conditions, or 2 or more comorbid conditions, and those who are obese. These groups should be considered higher priority for vaccination and for protective shielding when appropriate. Whilst odds ratios were high, the absolute increase in risk for most comorbidities was small compared to children without underlying conditions.

\section{Introduction}

Children and young people (CYP) have suffered fewer direct effects of the COVID-19 pandemic than adults, as the vast majority of CYP experience few if any symptoms of SARS-CoV-2 infection.(1) However a small minority experience more severe disease (2) and small numbers of deaths have been documented.(3) As severe outcomes amongst CYP are uncommon, our understanding of which are at risk from SARS-CoV-2 is limited, in contrast to adults. Yet identification of CYP at the highest risk from infection and its sequelae is essential for guiding clinicians, families and policymakers about who can safely attend school, and for identifying groups to be prioritised for vaccination.

SARS-CoV-2 infection in CYP has two primary manifestations. The first is acute COVID-19 disease, an acute illness caused by current infection with the virus and often characterised by respiratory symptoms. The second is a delayed inflammatory condition referred to as Paediatric Inflammatory Multisystem Syndrome Temporally associated with SARS-CoV-2 (PIMS-TS) or Multisystem Inflammatory Syndrome in Children (MIS-C)(4-6). Postulated risk factors for developing more severe COVID-19 or PIMS-TS / MIS-C include existing co-morbid conditions, age, sex, ethnicity, socio-economic group, and geographical location (7-10). Existing systematic evaluations are not useful for guiding policy as reviews were undertaken early in the pandemic (11-13), included highly heterogeneous groups and a wide range of outcomes from very small studies(14), and failed to distinguish between acute COVID-19 and PIMS-TS/MIS-C. Rapid growth in the literature over the past year provides an opportunity to synthesize findings, and better inform policy decisions about vaccination and protective shielding of vulnerable CYP.

We undertook a high-quality systematic review and meta-analysis of the literature from the first pandemic year to identify which CYP were at increased risk of severe disease or death in CYP admitted to hospital with SARS-CoV-2 infection or PIMS-TS / MIS-C. The study was limited to hospitalised CYP to enable the baseline denominator characteristics to be more accurately defined, particularly co-morbidities, and because in itself, hospital admission may be an indicator of severity. We limited our review to pre-specified potential risk-factors (co-morbidities, age, sex, ethnicity and deprivation), plus a limited number of outcomes denoting severe disease (critical care admission, need for mechanical invasive ventilation or cardiovascular support) and death. These are relevant to policy on protective shielding and school attendance, and potential vaccination strategies for CYP.

\section{Methods}

The protocol for this systematic review and meta-analysis was published on PROSPERO (CRD42021235338) on the $5^{\text {th }}$ February, 2021. We report findings according to the PRISMA 2020 guidelines(15) (Supplementary information 1).

Page 2/20 


\section{Search}

We performed a systematic search of four major databases: PubMed, European PMC, Scopus and Embase for relevant studies on COVID-19 in children and young people up to 21 years of age, published between the $1^{\text {st }}$ January 2020 and the $29^{\text {th }}$ January 2021 and updated the search on the $21^{\text {st }}$ May 2021. Searches were limited to English only and included key search concepts relating to COVID-19 OR SARS-CoV-2 OR PIMS-TS OR MIS-C AND Child OR Young person OR neonate (full search strategy in supplementary information 1). References of published systematic reviews and included studies were checked for additional studies.

\section{Study Selection}

Two reviewers selected studies using a two-stage process. All titles and abstracts were reviewed independently in duplicate by a team of five reviewers to determine eligibility. Full texts of articles were reviewed if inclusion was not clear in the abstract. Disagreements were discussed between the two reviewers and a decision made about inclusion or exclusion of the study. We excluded studies if the data were duplicated elsewhere, as reported by the study authors, and prioritised the studies which gave comparative data on the risk factors and outcomes of interest; if both did so, we used the larger study.

Inclusion criteria were as follows:

1. Observational studies of any type of CYP under 21 years of age who had been admitted to hospital with a finding of SARS-CoV-2 infection at or during admission by reverse transcriptase polymerase chain reaction (RT-PCR) OR who had been identified clinically as having PIMS-TS or MIS-C. Studies were eligible from institutions or from defined populations.

2. Data were provided on any of the following potential risk factors: age, sex, ethnicity, co-morbidity and socioeconomic deprivation.

3. Studies that included all admitted CYP in a population or institution regardless of co-morbidity were eligible for inclusion in the meta-analysis if they included 30 children with COVID-19 or 5 children with PIMS-TS or MIS-C. 30 children with COVID-19 was selected as the minimum a-priori to account for the outcomes of admission to critical care and death being rare, with previous systematic reviews suggesting severe COVID-19 occurs in approximately $2.5 \%$ of children(16). Studies of a single pre-existing co-morbidity were included in the systematic review if they included 5 children but not included in the meta-analysis.

4. Studies which reported one of the following outcomes as a proxy for severe disease:

(1) Need for invasive ventilation during hospital stay (not including during anaesthesia for surgical procedures)

(2) Need for cardiovascular support (vasopressors, inotropes +/- ECMO)

(3) Need for critical/intensive care

(4) Death after diagnosis of SARS-CoV-2 infection or PIMS-TS/MIS-C.

We initially intended to include other identifiers indicative of severe disease including use of pharmacological therapy and length of stay in critical care, but discarded these during the search as they were rarely and inconsistently reported. In analyses, CYP who did not have an indicator of severe disease but had COVID-19 or PIMS-TS/MIS-C and were admitted to hospital were used as the comparator group.

\section{Data Extraction for meta-analysis and Study Quality Assessment}

Data on risk factors and outcome variables were extracted from individual studies by one reviewer using a pre-designed data collection form and extraction was cross-checked by a second reviewer in $10 \%$ of studies. Authors of studies from the first search (to January 2021 ) were contacted by email and asked to provide either additional aggregated data demonstrating the relationship between predictor and outcome variables or IPD. Time did not allow these to be requested for studies identified in the second search (to May 2021). IPD were shared by authors using a standardised data collection form and checked for consistency with the original publication. Any queries from sharing authors or the study team were discussed over email or by a virtual video call. Eligible studies not supplying individual patient data in a way that enabled the relationship between risk factors and outcomes to be analysed or that did not provide aggregate or individual patient data were excluded from the meta-analysis.

\section{Assessment of Bias}


We assessed the studies for bias using the Newcastle-Ottawa Scale (17) to assess the quality of observational studies. Studies were scored according to selection of participants, comparability, and outcome. The description of comparator cohorts was deemed present when analyses comparing two groups of outcomes were described within the publication.

\section{Analysis}

Meta-analyses were undertaken separately for COVID-19 and PIMS-TS/MIS-C to examine the association of each clinical outcome with sex (female sex was the reference group), age-group (1-4 years as reference group) and comorbidities (children without any comorbidity were the reference group). Children who were RT-PCR positive for SARS-CoV-2 but met the criteria for PIMS-TS or MIS-C were included in the latter group.

Meta-analyses were conducted in two ways. First, we undertook a random-effects meta-analysis of reported study-level data using RevMan 5 software (18) to estimate pooled odds-ratios for each outcome (death, intensive care admission, mechanical invasive ventilation and cardiovascular support). We refer to this analysis as the aggregate meta-analysis. Age categories were described as $<1$ year, 1-4 years, 5-9 years, $10-14$ years and over 15 years and age 1-4 years used as the reference group. When studies reported a different age grouping, the group was used in the range which had the greatest cross-over of years. Co-morbidity data were compared using the presence and absence of individual co-morbidities. We calculated the ${ }^{2}$ statistic as a measure of heterogeneity and report prediction intervals. Funnel plots were examined to assess the evidence for publication bias. We then performed a sensitivity analysis by excluding the largest study of patients with COVID-19. The second set of meta-analyses were undertaken on the IPD, using multi-level logistic mixed-effects models in Stata 16 (StataCorp. College Station, TX) including a random effect for study, with models for comorbidities adjusted for age and sex. After each model we calculated the predicted probability for each outcome amongst those with and without each

comorbidity using the margins post estimation command. We did this to estimate risk difference for admission to critical care or death among CYP with comorbidities compared to those without. As a sensitivity analysis, a two-stage meta-analysis was conducted using study-level estimates calculated from the IPD data. A further sensitivity analysis for both the aggregate and IPD meta-analyses was performed by excluding one very large study.(19) Eligible studies which included only CYP with specific comorbidities were not included in the meta-analyses but included in a narrative synthesis. Data displayed are odds ratio (95\% confidence interval) and absolute risk difference ( $95 \%$ confidence interval).

\section{Results}

Figure 1 shows the search flow. 23,050 reports were identified. After excluding duplicates and ineligible studies, 81 studies were included in the review. 57 studies were included in the meta-analysis, including a total of 21,412 children (see Table 1). Nine studies were from Asia, fifteen from Europe, one from Africa, twenty-one from North America and eight from South America. One study had global recruitment.

Data from 22 studies (40\% of those in the meta-analysis) was included in the IPD meta-analyses, totalling 10,022 children. 26 studies reporting individual co-morbidities were eligible for inclusion in the narrative synthesis. Most studies eligible for inclusion in the meta-analysis were at considerable risk of bias (Figure 2).

We discuss findings from the aggregate and IPD meta-analyses for each set of risk factors and clinical outcomes below. Detailed data from included studies and pooled estimates from the aggregate meta-analyses are provided in Supplementary Table 1. Supplementary figures 1 and 2 show the sensitivity analysis with the largest study excluded. A two-stage meta-analysis using study-level estimates calculated from the IPD data is shown in supplementary figures 3 and 4 .

Proportions of hospitalised children with COVID-19 admitted to critical care and who died in the aggregate analysis were $21.8 \%$ and $5.9 \%$ respectively and for PIMS-TS/MIS-C were $60.4 \%$ and 5.2\%. In the IPD analysis, the proportion admitted to critical care with COVID-19 was 16.5\% (6.7, 26.3) with death reported in $2.1 \%(-0.1,4.3)$. For PIMS-TS/MIS-C, $72.6 \%(54.4,90.7)$ were admitted to critical care and $7.41 \%(4.0,10.8)$ died.

\section{Demographic risk factors for admission to critical care and death}

Sex was not associated with pooled risk of admission to critical care or death in either COVID-19 or PIMS-TS in either the aggregate or IPD analyses (Figure 3). Compared with 1-4 year olds, the aggregate analysis found a higher pooled risk of critical care admission amongst 10-14 year olds and a higher risk of death amongst infants for COVID-19. In contrast, the IPD analysis found higher risk of critical care and death amongst both infants and 10-14 year olds, plus a higher odds of death amongst those $>14$ years for COVID-19. For PIMS-TS/MIS-C, the aggregate analysis found higher odds of 
critical care admission in all age-groups over 5 years, but no age-effects on risk of death. Numbers in the IPD analysis for PIMS-TS/MIS-C were very small, with no association of age-group with risk of death or critical care admission.

We were unable to assess the impact of ethnicity and socioeconomic position on clinical outcomes. The reporting of ethnicity data was highly variable and groupings were insufficiently similar across studies to allow meta-analysis. Socioeconomic position was reported by very few studies.

\section{Association of co-morbidities and critical care and death in aggregate meta-analysis}

The aggregate meta-analysis compared those with any or specific comorbidities with all other children in each study (Figure 4). The presence of any comorbidity increased odds of critical care and death in COVID-19, with pooled odds ratios of $2.56(1.77,3.71)$ for critical care and 4.16 (1.97, 8.80) for death, both with moderate to high heterogeneity. Pooled odds ratios for PIMS-TS/MIS-C were of a similar order but with wide confidence intervals.

Pooled odds of both critical care admission and death in COVID-19 were increased in children with the following co-morbidities: cardiovascular; gastrointestinal or hepatic; neurological; chronic kidney disease; endocrine conditions, including diabetes; and metabolic conditions, including obesity. Odds ratios for critical care ranged from 2.5 to 3.1 and for death from 2.9 to 13 . The presence of asthma or trisomy 21 was not associated with either outcome, while respiratory conditions were associated with increased odds of critical care but not death. There was an increased odds of death but not of critical care admission in those with malignancy, haematological conditions and immunosuppression for non-malignant reasons.

Few individual comorbidities were associated with odds of critical care or death in PIMS-TS / MIS-C, with the exception of malignancy (OR for death 183 (2.61-12,815) and metabolic diseases including obesity (OR for critical care 1.45 (1.10-1.92)).

Association between co-morbidities and critical care and death in IPD meta-analysis

The IPD analysis compared those with each co-morbidity with children without any co-morbidity and additionally enabled analysis of risk associated with multiple comorbidities, obesity without other comorbidity, and trisomy 21 without cardiovascular disease. Figure 5 shows pooled OR for critical care and death for each comorbidity, and Figure 6 shows the risk difference estimated from the same models compared with children without comorbidities.

In IPD analysis, the presence of any comorbidity increased odds of critical care and death in COVID-19. The pooled odds ratio for admission to critical care was 1.64 (1.59-1.69), with risk difference being $4.6 \%(2.5,6.7)$ greater than the $16.2 \%$ prevalence of critical care admission in those without comorbidities. The pooled odds of death from COVID-19 in those with any comorbidity was $2.49(2.34-2.66)$, with a risk difference of $2.1 \%(-0.03,4.2)$ above the $1.69 \%$ risk in those without comorbidity. For PIMS-TS/MIS-C, pooled odds of critical care was 12.44 (9.74-15.87) and risk difference 21.1\% $(4.4,37.8)$ above baseline risk of $74.5 \%$, and pooled odds of death was $11.23(0.77,163.22)$ with risk difference $21.0 \%(-3.4,45.3)$ above baseline risk of death of $3.1 \%$.

Number of comorbidities increased the odds of critical care and death in COVID-19 in an apparently dose-dependent fashion, with those with $\geq 3$ comorbidities having a odds ratio of death of $4.98(3.78,6.56)$, twice that of the odds with one comorbidity. Small numbers with PIMS-TS / MIS-C meant that further analysis of co-morbidities could not be undertaken.

All individual comorbidities increased odds of admission to critical care except for malignancy and asthma, the latter associated with reduced odds $(-0.6 \%(-1.0,-0.2)$. Risk differences for critical care above the risk for the no comorbidities group were highest for cardiovascular, neurological, and gastrointestinal conditions, as well as for obesity. Obesity alone, without other conditions, increased risk difference to the same level as cardiovascular or neurological conditions, although numbers were small in the obesity analyses.

Odds of death in COVID-19 in the IPD analyses was elevated in all comorbidity groups except for asthma, where there was a reduced risk (-0.6\% (-0.9, -0.3)). Risk difference additional to the no comorbidity group was highest for malignancy. Trisomy 21 increased risk of death in those with or without comorbid cardiovascular disease. 
Twenty-six papers met the inclusion criteria for the narrative synthesis (Table 2), all reporting on the association of co-morbidity with acute COVID-19. Malignancy was the focus of sixteen of the studies, with rates of critical care admission in hospitalised patients ranging from $0-45 \%$ and of death in 0 $47 \%$. Six of the ten studies reporting deaths in this group of patients noted that some or all of the reported deaths were due to the underlying condition rather than SARS-CoV-2 infection.

Two studies focussed on hospitalised patients with sickle cell disease. There were fewer than fifteen patients in each study, with $17 \%$ of patients being admitted to critical care in one study and reported deaths in 0-10\%. Two studies looking at non-malignant immunosuppression described no children requiring critical care admission or death and a study of children with Rheumatic diseases found a rate of critical care admission of $38 \%$.

Chronic kidney disease was examined in two studies with small numbers of hospitalised patients, which describe a rate of critical care admission between $0-9 \%$ and of death between $0-6 \%$. A study of CYP with cystic fibrosis found that 1 in 24 (4\%) of those hospitalised were admitted to critical care and no deaths were described. Finally, two studies describe the association between pre-existing cardiac co-morbidity and outcome, which show a high proportion of children are admitted to critical care (43-71\%) and that $14-29 \%$ are reported to die.

\section{Discussion}

We present the first individual patient meta-analysis of risk factors for severe disease and death in CYP from both COVID-19 and PIMS-TS/MIS-C, nested within a broad systematic review and meta-analysis of published studies from the first pandemic year. Studies were of mixed quality and most were open to substantial bias; yet our meta-analyses included data from 57 studies from 19 countries, including 8 low or middle-income countries (LMIC).

Across both the aggregate and IPD analyses, we found no association between sex and odds of severe disease or death for either COVID-19 or PIMSTS/MIS-C. We found that odds of poor outcomes was 1.6 to 2-fold higher for infants than 1-4 year olds for COVID-19 alone, but that teenagers had elevated odds of severe COVID-19 (1.4 to 2.2-fold higher odds) and particularly PIMS-TS/MIS-C (2.5 to 8-fold greater odds).

The presence of underlying comorbid conditions were the strongest risk factors for critical care admission and death. The presence of any comorbidity increased odds of poor outcomes in COVID-19 for both the aggregate and IPD analyses, increasing absolute risk of critical care admission by $4.5 \%$ (a relative increase of $28 \%$ ) and risk of death by $2.5 \%$ (125\% relative increase), with an even greater $21 \%$ increase in risk of death for PIMS-TS/MIS-C (6.8fold increase in risk). Whilst one comorbidity increased absolute risk of critical care by $3.6 \%$ and death by $1.5 \%$ in COVID-19, 2 or more comorbidities dramatically increased the absolute risk increase.

All comorbidities were associated with increased risk across the two analyses, with the exception of asthma. Increase in odds of poor outcomes in COVID-19 was highest amongst those with cardiovascular, respiratory, neurological, and gastrointestinal comorbidities, each increasing absolute risk of critical care by $8-11 \%$ and risk of death by $1-3.5 \%$. Malignancy was associated with increased of death from COVID-19, but not critical care admission in both analyses, which is counter-intuitive and raises the possibility that this reflects the high mortality rate amongst cancer survivors who may have incidentally died with SARS-CoV-2 positivity. The aggregated analysis did not suggest increased risk in those with immunosuppression (outside malignancy) or with haematological conditions when compared to children without those comorbidities, but these groups were at increased risk in the IPD analysis.

The risk factors we identified for more severe COVID-19, older age and the presence of comorbidities, particularly cardiovascular, respiratory, neurological, and gastrointestinal comorbidities, and obesity, are highly similar to those risk factors now well described for adults.(20) This suggests that risk factors for severe COVID-19 are consistent across the life-course, but previously not well understood in CYP because of the rarity of severe disease. Our findings relate to risk factors for severe disease rather than risk factors for infection, as we included only hospitalised children. It is likely that our findings may over-estimate risks of critical care and death for CYP in high income countries, as the mortality rate in our analyses (2.1\% of children with COVID and 7.41\% of those with PIMS-TS/MIS-C) are very much higher than national mortality rates reported from these settings (21-23). This likely reflects inclusion of studies from LMIC and publication bias towards more severe cases. Despite this the additional absolute risks related to all comorbidities was small compared with those without comorbidities. 


\section{Comparison with the literature}

Our finding of no differences in risk by sex is contrary to a large literature showing that males are more vulnerable to severe illness and death in childhood $(24,25)$. Whilst male sex is a known risk factor for more severe COVID-19 in adults, this excess risk arises only after middle age (26). We found that obesity, whether alone or with other conditions, markedly increased risk of critical care admission and death in the IPD analysis. Whilst numbers with obesity were very small, our findings are consistent with adult data showing obesity to be one of the strongest risk factors for severe disease in adults(27).

Previous reviews have not provided a systematic understanding of the associations of paediatric comorbidities and severe outcomes in children. Systematic reviews which were undertaken early in the pandemic highlighted some of the challenges around identifying comorbidities which were associated with severe disease, including pooled reporting of even common conditions such as asthma(28) and a focus on individual comorbidities without a comparator group(29). Our finding that children with trisomy 21 were at increased risk of critical care admission and death has not been described before, although it is consistent with previous adult data(30). We found that this risk appears to operate both through and independently of cardiovascular anomalies, indicating that all CYP with trisomy 21 are at some increased risk of severe disease.

\section{Strengths and limitations}

We undertook a high quality systematic review and meta-analysis, including use of individual patient data to provide more detailed analysis of comorbidities, including obesity and trisomy 21 . Findings were largely consistent across the aggregate and the IPD analyses, with some exceptions. Findings from a sensitivity analysis excluding the largest study and from a two-stage meta-analysis of the IPD were highly similar to those described above.

Our data are subject to a number of limitations. Twenty-two of 57 studies (39\%) provided individual patient data; systematic differences between these groups may have introduced bias. There were very small numbers with PIMS-TS/MIS-C in some analyses, particularly the IPD analyses. We were unable to examine ethnicity and socioeconomic position as risk factors due to lack of data in included studies.

Included studies were highly heterogenous and from a wide range of resource settings, and it is likely that findings were influenced by differing national approaches to hospitalisation of infected children and by differences in availability and use of resources including intensive care beds. A number of East Asian countries hospitalised all children who were SARS-CoV-2 positive, regardless of symptoms, whilst other countries limited hospitalisation to symptomatic children or those with significant illness. Policies on admission to and access to critical care likely also differed between countries(31). The novel nature of PIMS-TS/MIS-C also likely influenced critical care admission thresholds for this condition. Definitions of comorbidities were also heterogenous across studies and some of our comorbidity groups may be subject to misclassification bias. The definition of obesity in most studies related to severe or extreme obesity rather than the more common condition of being overweight, yet obesity was undefined in a number of studies.

We were unable to separate the increased risk for severe disease related to comorbidities from the underlying risks of illness and death seen in these comorbidities in uninfected children, as all children in our study had SARS-CoV-2. Yet studies of infected hospitalised cohorts are essential to understand how rare congenital or acquired comorbidities may influence risk of severe disease or death from SARS-CoV-2

Whilst our review examined comorbidities as risk factors in more detail than previous studies, there were limited data on sub-types of comorbidities, e.g. whether neurological problems were epilepsy or more complex neurodisability, and on combinations of comorbidities. Our finding that cardiovascular, neurological, and gastrointestinal conditions were associated with the highest risk of poor outcome, a risk similar to having 2 or more comorbidities, may reflect that these conditions were more likely to be comorbid with others. Given the low risk to children requiring hospital admission or critical care as a direct consequence of SARS-CoV-2 infection, it is likely that a significant number of reported cases were coincidental cases of SARS-CoV-2 seropositivity reflecting population prevalence.

\section{Conclusions And Implications}


When children are admitted to hospital with SARS-CoV-2 infection, those at greatest risk of severe disease or death are teenagers, those with cardiac or neurological conditions, or 2 or more comorbid conditions, and children who are significantly obese. These groups should be considered higher priority for vaccination and for protective shielding when appropriate. Our findings suggest that established risk factors for severe disease in adults also operate in the early life-course. Whilst odd ratios for poor outcomes were increased for nearly all comorbidities in children, the absolute increase in risk for most comorbidities was small compared to children without underlying conditions. This emphasises that our findings should be understood within the broader context that risk of severe disease and death from COVID-19 and PIMS-TS/MIS-C in hospitalised children is very low compared with adults.

Our study quantifies the additional risk related to comorbidities in infected children, however it is likely that some or all of this risk relates to the underlying condition rather than SARS-CoV-2 infection. Further population-based research using comparator groups which identify the risk of severe disease due to COVID-19 and the underlying risk due to comorbidity is required to develop a safe approach to shielding and vaccination for children.

\section{Declarations}

\section{Acknowledgements}

We thank the authors who shared patient level data to enable their inclusion in this study (Supplementary Information 1) and the Royal College of Paediatrics and Child Health who assisted with data extraction.

\section{Contributions}

Study Design: RH, NT, CS, JW, C T-S, ML, MC, EW, PJD, KL, ESD, SK, LF and RMV, Literature search, identification of papers and data extraction: RH, HY, NT, CS, JW, SK and LF, Data analysis: RH, CT-S and RV, First Draft: RH, Review and editing: All authors

\section{Conflicts of interest}

All authors declare no competing interests.

\section{Funding}

No funding obtained for these analyses.

\section{Tables}

Table 1. Study characteristics of 'All comer' studies for CYP with COVID-19 and PIMS-TS or MIS-C included in meta-analyses, grouped by region of origin

Data Source: / if extracted from paper; * if individual patient data shared, ** if individual patient data shared and includes unpublished data due to ongoing data collection, \$ if individual patient data extracted from paper, @ if aggregate data shared by authors. Admission to critical care - CC, Required mechanical invasive ventilation - mIV, Required cardiovascular support - CVS. Systematic Review - SR. uk - unknown. 


\begin{tabular}{|c|c|c|c|c|c|c|c|c|c|c|}
\hline \multicolumn{2}{|l|}{ Study } & \multicolumn{2}{|c|}{ Population } & \multirow{2}{*}{$\begin{array}{l}\text { Exposure } \\
\text { Criteria } \\
\text { for } \\
\text { diagnosis }\end{array}$} & \multirow{2}{*}{$\begin{array}{l}\text { Risk Factors } \\
\text { used in MA }\end{array}$} & \multirow{2}{*}{$\begin{array}{l}\text { Outcomes } \\
\text { used in } \\
\text { MA }\end{array}$} & \multirow{2}{*}{$\begin{array}{l}\text { Comparator } \\
\text { Group (s) }\end{array}$} & \multirow{2}{*}{$\begin{array}{l}\mathrm{CC} \\
\mathrm{n}(\%)\end{array}$} & \multirow{2}{*}{$\begin{array}{l}\text { Death } \\
\mathrm{n}(\%)\end{array}$} & \multirow{2}{*}{$\begin{array}{l}\text { Data } \\
\text { Source }\end{array}$} \\
\hline $\begin{array}{l}\text { Author, Date, } \\
\text { Country }\end{array}$ & Study Design & $\begin{array}{l}\text { No of } \\
\text { admitted } \\
\text { children }\end{array}$ & $\begin{array}{l}\text { Inclusion } \\
\text { and } \\
\text { Exclusion } \\
\text { criteria }\end{array}$ & & & & & & & \\
\hline \multicolumn{11}{|l|}{ Asia } \\
\hline \multicolumn{11}{|l|}{ COVID-19 } \\
\hline $\begin{array}{l}\text { Du(32), May 2020, } \\
\text { China }\end{array}$ & $\begin{array}{l}\text { Retrospective } \\
\text { Observational }\end{array}$ & 182 & $\begin{array}{l}<16 \text { years } \\
\text { Admitted }\end{array}$ & $\begin{array}{l}\text { RT-PCR } \\
\text { pos }\end{array}$ & Age & $\begin{array}{l}\mathrm{mIV} n=3 \\
\text { Death } \\
\mathrm{n}=1\end{array}$ & $\begin{array}{l}\text { Allergic vs non- } \\
\text { allergic patients } \\
\text { Pneumonia vs no } \\
\text { pneumonia }\end{array}$ & uk & $\begin{array}{l}1 \\
(0.5 \%)\end{array}$ & 1 \\
\hline $\begin{array}{l}\text { Qian(33), July } \\
\text { 2020, China }\end{array}$ & $\begin{array}{l}\text { Retrospective } \\
\text { cohort }\end{array}$ & 127 & $\begin{array}{l}\text { 1month - } 16 \\
\text { years } \\
\text { Patients } \\
\text { admitted to } \\
\text { hospital }\end{array}$ & $\begin{array}{l}\text { RT-PCR } \\
\text { pos }\end{array}$ & $\begin{array}{l}\text { Age, sex, } \\
\text { comorbidity, } \\
\text { coinfection }\end{array}$ & $\begin{array}{l}\text { CC } n=7 \\
\text { Death } \\
n=0\end{array}$ & $\begin{array}{l}\text { Critical Disease } \\
\text { (admission to } \\
\text { CC/need for } \\
\text { mIV/CVS) - only } \\
\text { admission to CC } \\
\text { analysed. }\end{array}$ & $\begin{array}{l}7 \\
(5.5 \%)\end{array}$ & 0 & 1 \\
\hline $\begin{array}{l}\text { Kyung Sung(34), } \\
\text { July 202, South } \\
\text { Korea }\end{array}$ & $\begin{array}{l}\text { National } \\
\text { prospective } \\
\text { registry }\end{array}$ & 101 & $\begin{array}{l}\text { All ages } \\
\text { collected, } \\
\text { only children } \\
<19 \text { years } \\
\text { inc } \\
\end{array}$ & $\begin{array}{l}\text { RT-PCR } \\
\text { pos }\end{array}$ & $\begin{array}{l}\text { Age, sex, } \\
\text { comorbidities }\end{array}$ & $\begin{array}{l}\text { CC } n=0 \\
\text { mIV } n=0 \\
\text { Death } \\
n=0\end{array}$ & $\begin{array}{l}\text { Comparison of } \\
\text { disease } d=\text { severity }\end{array}$ & 0 & 0 & * \\
\hline $\begin{array}{l}\text { Alharbi(35), Dec } \\
\text { 2020, Saudi Arabia }\end{array}$ & $\begin{array}{l}\text { Retrospective } \\
\text { observational }\end{array}$ & $\begin{array}{l}65-\mathrm{C}-19 \\
6-\mathrm{MIS}-\mathrm{C}\end{array}$ & $\begin{array}{l}<15 \text { years } \\
\text { Community } \\
\text { and } \\
\text { hospitalised }\end{array}$ & $\begin{array}{l}\text { RT-PCR } \\
\text { pos } \\
\text { MIS-C } \\
\text { (CDC) }\end{array}$ & $\begin{array}{l}\text { Sex, } \\
\text { comorbidity }\end{array}$ & $\begin{array}{l}\text { CC } n=12 \\
\text { mIV n=5 } \\
\text { CVS n=8 } \\
\text { Death } \\
n=3\end{array}$ & $\begin{array}{l}\text { Community vs } \\
\text { hospitalised, } \\
\text { hospitalised vs } \\
\text { critical care, }\end{array}$ & $\begin{array}{l}12 \\
(17 \%)\end{array}$ & $\begin{array}{l}3 \\
(4 \%)\end{array}$ & 1 \\
\hline $\begin{array}{l}\text { Bayesheva(36), } \\
\text { Dec 2020, } \\
\text { Kazakhstan }\end{array}$ & $\begin{array}{l}\text { Retrospective } \\
\text { Observational }\end{array}$ & 549 & $<19$ years & $\begin{array}{l}\text { RT-PCR } \\
\text { pos }\end{array}$ & $\begin{array}{l}\text { Comorbidity, } \\
\text { age, sex } \\
\text { Obesity not } \\
\text { defined }\end{array}$ & $\begin{array}{l}\text { CC } \mathrm{n}=4 \\
\mathrm{mIV} \mathrm{n}=1 \\
\text { Death } \\
\mathrm{n}=0\end{array}$ & $\begin{array}{l}\text { Mild, moderate and } \\
\text { severe disease }\end{array}$ & $\begin{array}{l}4 \\
(0.7 \%)\end{array}$ & 0 & $*$ \\
\hline $\begin{array}{l}\text { Qian(37), April } \\
\text { 2021, China }\end{array}$ & $\begin{array}{l}\text { Retrospective } \\
\text { cohort }\end{array}$ & 127 & $\begin{array}{l}1 \text { month - } 16 \\
\text { years }\end{array}$ & $\begin{array}{l}\text { RT-PCR } \\
\text { pos }\end{array}$ & Co-morbidities & Death & $\begin{array}{l}\text { Mild, moderate, } \\
\text { severe and critical }\end{array}$ & uk & \begin{tabular}{|l|}
2 \\
$(1.6 \%)$ \\
\end{tabular} & 1 \\
\hline \multicolumn{11}{|l|}{ PIMS-TS / MIS-C } \\
\hline $\begin{array}{l}\text { Almoussa(38), Oct } \\
\text { 2020, Saudi Arabia }\end{array}$ & $\begin{array}{l}\text { Retrospective } \\
\text { case series }\end{array}$ & 10 & $\begin{array}{l}<14 \text { years } \\
\text { Admitted to } \\
\text { hospital }\end{array}$ & $\begin{array}{l}\text { MIS-C } \\
\text { (CDC) }\end{array}$ & $\begin{array}{l}\text { Age, sex } \\
\text { comorbidity }\end{array}$ & $\begin{array}{l}\text { CC } \mathrm{n}=9 \\
\mathrm{mIV} \mathrm{n}=1 \\
\text { CVS } \mathrm{n}=5 \\
\text { Death } \\
\mathrm{n}=2\end{array}$ & None & $\begin{array}{l}9 \\
(90 \%)\end{array}$ & $\begin{array}{l}2 \\
(20 \%)\end{array}$ & $\$$ \\
\hline $\begin{array}{l}\text { Jain(39), Aug 2020, } \\
\text { India }\end{array}$ & $\begin{array}{l}\text { Retrospective } \\
\text { and } \\
\text { prospective } \\
\text { observational }\end{array}$ & 23 & $\begin{array}{l}<15 \text { years } \\
\text { Hospitalised }\end{array}$ & $\begin{array}{l}\text { MIS-C } \\
(\mathrm{WHO})\end{array}$ & Sex, age & $\begin{array}{l}m I V n=9 \\
\text { CVS } n=15 \\
\text { Death } \\
n=1\end{array}$ & $\begin{array}{l}\text { MIS-C with shock vs } \\
\text { MIS-C without shock }\end{array}$ & uk & $\begin{array}{l}1 \\
(4 \%)\end{array}$ & * \\
\hline $\begin{array}{l}\text { Shahbaznejad (40), } \\
\text { Oct 2020, Iran }\end{array}$ & $\begin{array}{l}\text { Retrospective } \\
\text { cohort }\end{array}$ & 10 & $\begin{array}{l}\text { Patients } \\
\text { admitted to } \\
\text { hospital }\end{array}$ & PIMS-TS & Sex, Age & $\begin{array}{l}\text { CC } \mathrm{n}=9 \\
\mathrm{mIV} \mathrm{n}=3 \\
\text { CVS } \mathrm{n}=4 \\
\text { Death } \\
\mathrm{n}=1\end{array}$ & None & $\begin{array}{l}9 \\
(90 \%)\end{array}$ & $\begin{array}{l}1 \\
(10 \%)\end{array}$ & $\$$ \\
\hline $\begin{array}{l}\text { Hasan (41), Feb } \\
\text { 2021, Qatar }\end{array}$ & $\begin{array}{l}\text { Retrospective } \\
\text { cohort }\end{array}$ & 7 & $\begin{array}{l}\text { Patients } \\
\text { admitted to } \\
\text { hospital } \\
\end{array}$ & $\begin{array}{l}\text { MIS-C } \\
(\mathrm{WHO})\end{array}$ & Sex, Age & $\begin{array}{l}\text { CC } n=5 \\
m I V ~ n=1\end{array}$ & None & $\begin{array}{l}5 \\
(71 \%)\end{array}$ & uk & $\$$ \\
\hline \multicolumn{11}{|l|}{ Europe } \\
\hline \multicolumn{11}{|l|}{ COVID-19 } \\
\hline $\begin{array}{l}\text { Armann(42), May } \\
\text { 2020, Germany }\end{array}$ & $\begin{array}{l}\text { Prospective } \\
\text { Observational } \\
\text { Registry }\end{array}$ & 102 & $<20$ years & $\begin{array}{l}\text { RT-PCR } \\
\text { pos }\end{array}$ & $\begin{array}{l}\text { Age, sex, } \\
\text { comorbidities } \\
\text { Obesity not } \\
\text { defined }\end{array}$ & $\begin{array}{l}\text { CC } n=15 \\
\text { mIV } n=6 \\
\text { CVS } n=8 \\
\text { Death } \\
n=1\end{array}$ & None & 15 & 1 & $*$ \\
\hline $\begin{array}{l}\text { Bellino (43), July } \\
\text { 2020, Italy }\end{array}$ & $\begin{array}{l}\text { Routine } \\
\text { surveillance } \\
\text { system }\end{array}$ & 511 & $\begin{array}{l}<18 \text { years } \\
\text { Admitted }\end{array}$ & $\begin{array}{l}\text { RT-PCR } \\
\text { pos }\end{array}$ & $\begin{array}{l}\text { Age, sex, } \\
\text { comorbidity }\end{array}$ & $\begin{array}{l}\text { CC } n=18 \\
\text { Death } \\
n=4\end{array}$ & $\begin{array}{l}\text { Outcomes compared } \\
\text { by age. Multivariable } \\
\text { logistic regression } \\
\text { comparing predictor } \\
\text { variables and } \\
\text { outcomes }\end{array}$ & 18 & 4 & 1 \\
\hline $\begin{array}{l}\text { Giacomet(44), Oct } \\
\text { 2020, Italy }\end{array}$ & $\begin{array}{l}\text { Retrospective } \\
\text { observational }\end{array}$ & 127 & $\begin{array}{l}<18 \text { years } \\
\text { Admitted }\end{array}$ & $\begin{array}{l}\text { RT-PCR } \\
\text { pos }\end{array}$ & $\begin{array}{l}\text { Sex, } \\
\text { comorbidity, } \\
\text { ethnicity } \\
\text { Obesity not } \\
\text { defined }\end{array}$ & $\begin{array}{l}\mathrm{CC} n=8 \\
\mathrm{mIV}, \mathrm{n}=1\end{array}$ & $\begin{array}{l}\text { Asymptomatic, mild } \\
\text { or moderate vs } \\
\text { severe or critical. } \\
\text { Admission to ICU/no } \\
\text { ICU. }\end{array}$ & 8 & 0 & * \\
\hline $\begin{array}{l}\text { Gazzarino(45), } \\
\text { May 2020, Italy }\end{array}$ & $\begin{array}{l}\text { Retrospective } \\
\text { observational }\end{array}$ & 168 & $\begin{array}{l}1 \text { day }-<18 \\
\text { years } \\
\text { Admitted }\end{array}$ & $\begin{array}{l}\text { RT-PCR } \\
\text { pos }\end{array}$ & Age & $\mathrm{mIV} n=2$ & None & uk & uk & I \\
\hline $\begin{array}{l}\text { Ceano-Vivas(46), } \\
\text { May 2020, Spain }\end{array}$ & $\begin{array}{l}\text { Retrospective } \\
\text { Observational }\end{array}$ & 33 & $\begin{array}{l}<18 \text { years } \\
\text { Presenting } \\
\text { to hospital }\end{array}$ & $\begin{array}{l}\text { RT-PCR } \\
\text { pos }\end{array}$ & $\begin{array}{l}\text { Sex, } \\
\text { comorbidity, } \\
\text { age } \\
\text { Obesity: not } \\
\text { defined }\end{array}$ & $\begin{array}{l}\text { CC } n=5 \\
m I V n=1 \\
\text { CVS } n=1 \\
\text { Death } \\
n=1\end{array}$ & Admission to hospital & 5 & 1 & $*$ \\
\hline
\end{tabular}




\begin{tabular}{|c|c|c|c|c|c|c|c|c|c|c|}
\hline \multicolumn{2}{|l|}{ Study } & \multicolumn{2}{|c|}{ Population } & \multirow{2}{*}{$\begin{array}{l}\text { Exposure } \\
\text { RT-PCR } \\
\text { post or IgG } \\
\text { antibodies }\end{array}$} & \multirow{2}{*}{$\begin{array}{l}\text { Risk Factors } \\
\text { used in MA } \\
\text { Age }\end{array}$} & \multirow{2}{*}{$\begin{array}{l}\text { Outcomes } \\
\text { used in } \\
\text { MA } \\
\text { CC } n=14\end{array}$} & \multirow{2}{*}{$\begin{array}{l}\text { Comparator } \\
\text { Group(s) } \\
\text { Uncomplicated vs } \\
\text { complicated (fluids } \\
\text { or vasopressors, } \\
\text { high flow nasal } \\
\text { cannulae / non- } \\
\text { invasive ventilation / } \\
\text { invasive ventilation, } \\
\text { encephalopathy). }\end{array}$} & \multirow{2}{*}{$\begin{array}{l}\mathrm{CC} \\
\mathrm{n}(\%) \\
14\end{array}$} & \multirow{2}{*}{$\begin{array}{l}\begin{array}{l}\text { Death } \\
\text { n(\%) }\end{array} \\
\text { uk }\end{array}$} & \multirow{2}{*}{$\begin{array}{l}\begin{array}{l}\text { Data } \\
\text { Source }\end{array} \\
/\end{array}$} \\
\hline $\begin{array}{l}\text { Storch de } \\
\text { Gracia(47), Oct } \\
\text { 2020, Spain }\end{array}$ & $\begin{array}{l}\text { Retrospective } \\
\text { observational }\end{array}$ & 39 & $\begin{array}{l}<18 \text { years } \\
\text { requiring } \\
\text { hospital } \\
\text { admission. } \\
\text { Includes } \\
\text { patients with } \\
\text { MIS-C. } \\
\text { Exclusion: } \\
\text { pre-existing } \\
\text { oncological } \\
\text { disease, } \\
\text { incidental or } \\
\text { nosocomial } \\
\text { SARS-CoV-2 }\end{array}$ & & & & & & & \\
\hline $\begin{array}{l}\text { M Korkmaz(48), } \\
\text { June 2020, Turkey }\end{array}$ & $\begin{array}{l}\text { Retrospective } \\
\text { cohort }\end{array}$ & 44 & $\begin{array}{l}<18 \text { years } \\
\text { All patients } \\
\text { attending ED }\end{array}$ & $\begin{array}{l}\text { RT-PCR } \\
\text { pos }\end{array}$ & Age & $\mathrm{CC} n=2$ & $\begin{array}{l}\text { Admission to hospital } \\
\text { vs discharge from } \\
\text { ED, } \\
5 \text { years, > }>\text { years }\end{array}$ & 2 & uk & 1 \\
\hline $\begin{array}{l}\text { Yayla(49), March } \\
\text { 2021, Turkey }\end{array}$ & $\begin{array}{l}\text { Retrospective } \\
\text { Observational }\end{array}$ & 77 & $\begin{array}{l}<18 \text { years } \\
\text { Admitted }\end{array}$ & $\begin{array}{l}\text { RT-PCR } \\
\text { pos or } \\
\text { antibodies }\end{array}$ & Comorbidity & $\begin{array}{l}\text { CC } \mathrm{n}=1 \\
\mathrm{mIV} \mathrm{n}=1 \\
\text { CVS } \mathrm{n}=1 \\
\text { Death } \\
\mathrm{n}=1 \\
\end{array}$ & $\begin{array}{l}\text { Asymptomatic, mild, } \\
\text { moderate, } \\
\text { critical/severe }\end{array}$ & 1 & 1 & 1 \\
\hline $\begin{array}{l}\text { O Swann(7), Aug } \\
\text { 2020, UK }\end{array}$ & $\begin{array}{l}\text { Prospective } \\
\text { Observational }\end{array}$ & 579 & $\begin{array}{l}<19 \text { years } \\
\text { Admitted to } \\
\text { hospital. } \\
\text { (Patients } \\
\text { with MIS-C } \\
\text { were } \\
\text { excluded } \\
\text { from SR) }\end{array}$ & $\begin{array}{l}\text { RT-PCR } \\
\text { pos }\end{array}$ & $\begin{array}{l}\text { Age, sex, } \\
\text { comorbidities } \\
\text { Obesity not } \\
\text { defined }\end{array}$ & $\begin{array}{l}\text { CC } n=78 \\
\text { Death } \\
n=6\end{array}$ & $\begin{array}{l}\text { Admission to critical } \\
\text { care, in-hospital } \\
\text { mortality. } \\
\text { Details about } \\
\text { patients with MIS-C } \\
\text { could not be } \\
\text { extracted and were } \\
\text { excluded. }\end{array}$ & 78 & 6 & 1 \\
\hline $\begin{array}{l}\text { Gotzinger(8), June } \\
\text { 2020, Europe }\end{array}$ & $\begin{array}{l}\text { Retrospective } \\
\text { and } \\
\text { prospective } \\
\text { observational }\end{array}$ & 582 & $\begin{array}{l}<19 \text { years } \\
\text { Admitted } \\
\text { and } \\
\text { community }\end{array}$ & $\begin{array}{l}\text { RT-PCR } \\
\text { pos }\end{array}$ & $\begin{array}{l}\text { Sex, } \\
\text { comorbidity, } \\
\text { age } \\
\text { Obesity not } \\
\text { defined }\end{array}$ & $\begin{array}{l}\text { CC } n=48 \\
\text { mIV n=25 } \\
\text { CVS n=19 } \\
\text { Death } \\
n=4\end{array}$ & $\begin{array}{l}\text { Admission to CC / no } \\
\text { CC }\end{array}$ & $\begin{array}{l}48 \\
(8.2 \%)\end{array}$ & $\begin{array}{l}4 \\
(0.7 \%)\end{array}$ & (a) \\
\hline $\begin{array}{l}\text { Moraleda(50), July } \\
\text { 2020, Spain }\end{array}$ & $\begin{array}{l}\text { Retrospective } \\
\text { case series }\end{array}$ & 31 & $\begin{array}{l}<18 \text { years } \\
\text { Admitted to } \\
\text { hospital }\end{array}$ & $\begin{array}{l}\text { RT-PCR, } \\
\text { IgM or IgG } \\
\text { positive or } \\
\text { clinical } \\
\text { MIS-C } \\
\end{array}$ & Comorbidities & $\begin{array}{l}\text { Death } \\
n=1\end{array}$ & None & $\begin{array}{l}20 \\
(65 \%)\end{array}$ & $\begin{array}{l}1 \\
(3 \%)\end{array}$ & 1 \\
\hline \multicolumn{11}{|l|}{ PIMS-TS / MIS-C } \\
\hline $\begin{array}{l}\text { Whittaker(4), June } \\
\text { 2020, UK }\end{array}$ & $\begin{array}{l}\text { Retrospective } \\
\text { cohort }\end{array}$ & 58 & $\begin{array}{l}\text { Patients } \\
\text { admitted to } \\
\text { hospital } \\
<18 \text { years }\end{array}$ & PIMS-TS & $\begin{array}{l}\text { Sex, } \\
\text { comorbidity }\end{array}$ & $\begin{array}{l}\text { CC } n=32 \\
\text { mIV } n=26 \\
\text { CVS } n=27 \\
\text { Death } \\
n=1\end{array}$ & $\begin{array}{l}\text { Comparison with } \\
\text { other childhood } \\
\text { inflammatory } \\
\text { disorders }\end{array}$ & $\begin{array}{l}32 \\
(55 \%)\end{array}$ & $\begin{array}{l}1 \\
(1.7 \%)\end{array}$ & (a) \\
\hline Pang(51), UK & $\begin{array}{l}\text { Retrospective } \\
\text { selected } \\
\text { cohort }\end{array}$ & 5 & $\begin{array}{l}\text { Patients } \\
\text { admitted to } \\
\text { hospital } \\
<16 \text { years }\end{array}$ & PIMS-TS & $\begin{array}{l}\text { Sex, age, } \\
\text { comorbidity, } \\
\text { race }\end{array}$ & $\begin{array}{l}\text { CC } n=4 \\
m I V n=4\end{array}$ & $\begin{array}{l}\text { Viral polymorphisms } \\
\text { in admitted patients } \\
\text { with and without } \\
\text { PIMS-TS compared } \\
\text { to community SARS- } \\
\text { CoV-2 individuals }\end{array}$ & $\begin{array}{l}4 \\
(80 \%)\end{array}$ & $\begin{array}{l}4 \\
(80 \%)\end{array}$ & $\$$ \\
\hline $\begin{array}{l}\text { Carbajal(52), Nov } \\
\text { 2020, France }\end{array}$ & $\begin{array}{l}\text { Retrospective } \\
\text { observational }\end{array}$ & 7 & $\begin{array}{l}\text { Hospitalised } \\
<18 \text { years }\end{array}$ & $\begin{array}{l}\text { MIS-C } \\
\text { (CDC) }\end{array}$ & Sex, age & $\begin{array}{l}\text { CC } n=7 \\
\text { mIV } n=3 \\
\text { CVS } n=5 \\
\text { Death } \\
n=0\end{array}$ & $\begin{array}{l}\text { Kawasaki disease } \\
\text { compared to MIS-C } \\
\text { Comparison of MIS- } \\
\text { C (CDC) vs MIS-C } \\
\text { (WHO) vs PIMS-TS }\end{array}$ & $\begin{array}{l}7 \\
(100 \%)\end{array}$ & 0 & $\$$ \\
\hline $\begin{array}{l}\text { Alkan(53), March } \\
\text { 2021, Turkey }\end{array}$ & $\begin{array}{l}\text { Retrospective } \\
\text { observational }\end{array}$ & 36 & $\begin{array}{l}\text { Hospitalised } \\
<18 \text { years } \\
\end{array}$ & $\begin{array}{l}\text { MIS-C } \\
(\mathrm{CDC}) \\
\end{array}$ & Age & $\mathrm{CC}$ & $\begin{array}{l}\text { Mild, moderate and } \\
\text { severe MIS-C }\end{array}$ & $\begin{array}{ll}4 \\
(11 \%) \\
\end{array}$ & 0 & 1 \\
\hline \multicolumn{11}{|l|}{ Africa } \\
\hline \multicolumn{11}{|l|}{ COVID-19 } \\
\hline $\begin{array}{l}\text { van der Zalm(54), } \\
\text { Nov 2020, South } \\
\text { Africa }\end{array}$ & $\begin{array}{l}\text { Retrospective } \\
\text { Observational }\end{array}$ & 62 & $\begin{array}{l}<13 \text { years } \\
\text { Exclusion: } \\
\text { MIS-C }\end{array}$ & $\begin{array}{l}\text { RT-PCR } \\
\text { pos }\end{array}$ & Age & $\begin{array}{l}\text { CC } n=11 \\
\text { mIV } n=4 \\
\text { Death } \\
n=1\end{array}$ & $\begin{array}{l}\text { Outcomes compared } \\
\text { based on age }\end{array}$ & $\begin{array}{l}11 \\
(18 \%)\end{array}$ & $\begin{array}{l}1 \\
(1.6 \%)\end{array}$ & 1 \\
\hline \multicolumn{11}{|l|}{ North America } \\
\hline \multicolumn{11}{|l|}{ COVID-19 } \\
\hline $\begin{array}{l}\text { CDC(55), April } \\
\text { 2020, USA }\end{array}$ & $\begin{array}{l}\text { Voluntary } \\
\text { national } \\
\text { reporting }\end{array}$ & 147 & $<18$ years & $\begin{array}{l}\text { RT-PCR } \\
\text { pos }\end{array}$ & Age & CC $n=15$ & $\begin{array}{l}\text { Comparison with } \\
\text { adults }\end{array}$ & $\begin{array}{l}15 \\
(10 \%)\end{array}$ & uk & 1 \\
\hline $\begin{array}{l}\text { Chao(56), Aug } \\
\text { 2020, USA }\end{array}$ & $\begin{array}{l}\text { Retrospective } \\
\text { Observational }\end{array}$ & 46 & $\begin{array}{l}1 \text { month - } \\
<22 \text { years } \\
\text { Admitted }\end{array}$ & $\begin{array}{l}\text { RT-PCR } \\
\text { pos }\end{array}$ & $\begin{array}{l}\text { Sex, } \\
\text { comorbidity } \\
\text { Obesity: BMI } \\
>30 \mathrm{~kg} / \mathrm{m}^{2}\end{array}$ & CC $n=13$ & $\begin{array}{l}\text { Admission to critical } \\
\text { care }\end{array}$ & $\begin{array}{l}13 \\
(28 \%)\end{array}$ & uk & 1 \\
\hline $\begin{array}{l}\text { Desai(57), Dec } \\
\text { 2020, USA }\end{array}$ & $\begin{array}{l}\text { Retrospective } \\
\text { Observational }\end{array}$ & 293 & $\begin{array}{l}<18 \text { years } \\
\text { Presenting } \\
\text { to hospital }\end{array}$ & $\begin{array}{l}\text { RT-PCR } \\
\text { pos }\end{array}$ & $\begin{array}{l}\text { Sex, } \\
\text { comorbidity }\end{array}$ & $\mathrm{mIV} n=27$ & $\begin{array}{l}\text { Admission to hospital } \\
\text { Admission to critical } \\
\text { care }\end{array}$ & $\begin{array}{l}28 \\
(9.5 \%)\end{array}$ & Uk & 1 \\
\hline
\end{tabular}




\begin{tabular}{|c|c|c|c|c|c|c|c|c|c|c|}
\hline \multicolumn{2}{|l|}{ Study } & \multicolumn{2}{|l|}{ Population } & \multirow{2}{*}{$\begin{array}{l}\text { Exposure } \\
\begin{array}{l}\text { RT-PCR } \\
\text { pos }\end{array}\end{array}$} & \multirow{2}{*}{$\begin{array}{l}\text { Risk Factors } \\
\text { used in MA } \\
\begin{array}{l}\text { Sex, } \\
\text { comorbidity }\end{array} \\
\text { Obesity: } \\
\begin{array}{l}\text { BMI 95th } \\
\text { percentile }\end{array}\end{array}$} & \multirow{2}{*}{$\begin{array}{l}\text { Outcomes } \\
\text { used in } \\
\text { MA } \\
\text { CC } n=30\end{array}$} & \multirow{2}{*}{$\begin{array}{l}\text { Comparator } \\
\text { Group(s) } \\
\begin{array}{l}\text { Admission to critical } \\
\text { care }\end{array}\end{array}$} & \multirow{2}{*}{$\begin{array}{l}\text { CC } \\
\text { n(\%) } \\
30 \\
(39 \%)\end{array}$} & \multirow{2}{*}{$\begin{array}{l}\text { Death } \\
\mathrm{n}(\%) \\
1 \\
(1.2 \%)\end{array}$} & \multirow{2}{*}{$\begin{array}{l}\text { Data } \\
\text { Source } \\
\text { / }\end{array}$} \\
\hline $\begin{array}{l}\text { Fisler(58), Dec } \\
\text { 2020, USA }\end{array}$ & $\begin{array}{l}\text { Retrospective } \\
\text { Observational }\end{array}$ & 77 & $\begin{array}{l}<21 \text { years } \\
\text { Admitted }\end{array}$ & & & & & & & \\
\hline $\begin{array}{l}\text { Kainth(59), July } \\
\text { 2020, USA }\end{array}$ & $\begin{array}{l}\text { Retrospective } \\
\text { observational }\end{array}$ & 65 & $\begin{array}{l}<22 \text { years } \\
\text { Admitted } \\
\text { Symptomatic }\end{array}$ & $\begin{array}{l}\text { RT-PCR } \\
\text { pos }\end{array}$ & $\begin{array}{l}\text { Sex, age, } \\
\text { comorbidity }\end{array}$ & CC $n=23$ & $\begin{array}{l}\text { Subcategories of } \\
\text { healthy infants, } \\
\text { healthy children, } \\
\text { immunocompromised } \\
\text { children, chronically } \\
\text { ill children and mild, } \\
\text { moderate or severe } \\
\text { disease. }\end{array}$ & $\begin{array}{l}23 \\
(35 \%)\end{array}$ & $\begin{array}{l}1 \\
(1.5 \%)\end{array}$ & 1 \\
\hline $\begin{array}{l}\text { Marcello(60), Dec } \\
\text { 2020, USA }\end{array}$ & $\begin{array}{l}\text { Retrospective } \\
\text { observational }\end{array}$ & 32 & $\begin{array}{l}\text { All ages } \\
\text { included, } \\
\text { data } \\
\text { provided on } \\
\text { children < } \\
19 \text { years } \\
\end{array}$ & $\begin{array}{l}\text { RT-PCR } \\
\text { pos }\end{array}$ & $\begin{array}{l}\text { Sex, } \\
\text { comorbidity }\end{array}$ & $\begin{array}{l}\text { Death } \\
n=1\end{array}$ & $\begin{array}{l}\text { Hospitalisation and } \\
\text { death }\end{array}$ & & $\begin{array}{l}1 \\
(3.1 \%)\end{array}$ & $*$ \\
\hline $\begin{array}{l}\text { Kim(61), Aug 2020, } \\
\text { USA }\end{array}$ & $\begin{array}{l}\text { Population } \\
\text { surveillance } \\
\text { database }\end{array}$ & $\begin{array}{l}208 \\
\text { (completed } \\
\text { data) }\end{array}$ & $\begin{array}{l}<18 \text { years } \\
\text { Hospitalised }\end{array}$ & $\begin{array}{l}\text { RT-PCR } \\
\text { pos }\end{array}$ & Age & $\begin{array}{l}\text { CC } n=69 \\
\text { mIV } n=12 \\
\text { CVS } n=10 \\
\text { Death } \\
n=1\end{array}$ & $\begin{array}{l}\text { Outcomes compared } \\
\text { by age. }\end{array}$ & $\begin{array}{l}69 \\
(33 \%)\end{array}$ & $\begin{array}{l}1 \\
(0.5 \%)\end{array}$ & 1 \\
\hline $\begin{array}{l}\text { Moreira(10), Jan } \\
\text { 2021, USA }\end{array}$ & $\begin{array}{l}\text { Routinely } \\
\text { collected data }\end{array}$ & 445 & $\begin{array}{l}\text { All data } \\
\text { complete } \\
<20 \text { years } \\
\text { All patients } \\
\text { attending ED }\end{array}$ & $\begin{array}{l}\text { RT-PCR } \\
\text { pos }\end{array}$ & $\begin{array}{l}\text { Age (0-9 } \\
\text { years, 10-19 } \\
\text { years), } \\
\text { Gender, Race } \\
\text { \& ethnicity, } \\
\text { comorbidity }\end{array}$ & $\begin{array}{l}\text { CC } n=69 \\
\text { Death } \\
n=12\end{array}$ & $\begin{array}{l}\text { Admission to hospital } \\
\text { vs discharge from } \\
\text { ED, } \\
\text { Death }\end{array}$ & $\begin{array}{l}69 \\
(16 \%)\end{array}$ & $\begin{array}{l}12 \\
(2.7 \%)\end{array}$ & $*$ \\
\hline $\begin{array}{l}\text { Richardson(62), } \\
\text { April 2020, USA }\end{array}$ & $\begin{array}{l}\text { Prospective } \\
\text { cohort }\end{array}$ & 110 & $\begin{array}{l}\text { Patients } \\
\text { admitted to } \\
\text { hospital } \\
\text { No age } \\
\text { restriction } \\
\text { (patients } \\
\text { included }<19 \\
\text { years) } \\
\end{array}$ & $\begin{array}{l}\text { RT-PCR } \\
\text { pos }\end{array}$ & $\begin{array}{l}\text { Sex, } \\
\text { comorbidities, } \\
\text { Age, Race }\end{array}$ & $\begin{array}{l}\text { CC } n=37 \\
\text { mIV n=14 } \\
\text { CVS } n=0 \\
\text { Death } \\
n=1\end{array}$ & Survival vs death & $\begin{array}{l}37 \\
(34 \%)\end{array}$ & $\begin{array}{l}1 \\
(0.9 \%)\end{array}$ & $*$ \\
\hline $\begin{array}{l}\text { Verma(63), Jan } \\
\text { 2021, USA }\end{array}$ & $\begin{array}{l}\text { Retrospective } \\
\text { Observational }\end{array}$ & 82 & $\begin{array}{l}<22 \text { years } \\
\text { Admitted }\end{array}$ & $\begin{array}{l}\text { RT-PCR } \\
\text { pos }\end{array}$ & $\begin{array}{l}\text { Age, } \\
\text { comorbidity } \\
\text { Obesity: } \\
\text { BMI } 30 \text { or } 95^{\text {th }} \\
\text { percentile }\end{array}$ & $\begin{array}{l}\text { CC } \mathrm{n}=23 \\
\mathrm{mIV} \mathrm{n}=7 \\
\text { Death } \\
\mathrm{n}=0\end{array}$ & $\begin{array}{l}\text { Admission to critical } \\
\text { care }\end{array}$ & $\begin{array}{l}23 \\
(28 \%)\end{array}$ & 0 & 1 \\
\hline $\begin{array}{l}\text { Zachariah(64), } \\
\text { June 2020, USA }\end{array}$ & $\begin{array}{l}\text { Retrospective } \\
\text { Observational }\end{array}$ & 50 & $\begin{array}{l}<22 \text { years } \\
\text { Admitted }\end{array}$ & $\begin{array}{l}\text { RT-PCR } \\
\text { pos } \\
\end{array}$ & $\begin{array}{l}\text { Sex, } \\
\text { comorbidity }\end{array}$ & $\mathrm{mIV} n=9$ & $\begin{array}{l}\text { Non-severe vs } \\
\text { severe }\end{array}$ & uk & $\mathrm{uk}$ & 1 \\
\hline $\begin{array}{l}\text { Graff(65), April } \\
\text { 2021, USA }\end{array}$ & $\begin{array}{l}\text { Retrospective } \\
\text { Observational }\end{array}$ & 85 & $\begin{array}{l}<21 \text { years, } \\
\text { all patients } \\
\text { (admitted } \\
\text { only in MA) }\end{array}$ & $\begin{array}{l}\text { RT-PCR } \\
\text { pos }\end{array}$ & $\begin{array}{l}\text { Age, sex, race, } \\
\text { comorbidity } \\
\text { Obesity: } \\
\text { BMI 95 } \\
\text { percentile } \\
\end{array}$ & CC $n=11$ & $\begin{array}{l}\text { Non-severe vs } \\
\text { severe }\end{array}$ & $\begin{array}{l}11 \\
(13 \%)\end{array}$ & $\begin{array}{l}1 \\
(1.2 \%)\end{array}$ & 1 \\
\hline $\begin{array}{l}\text { Preston(66), April } \\
\text { 2021, USA }\end{array}$ & $\begin{array}{l}\text { Routinely } \\
\text { collected data }\end{array}$ & 2430 & $\begin{array}{l}<19 \text { years, } \\
\text { all patients } \\
\text { (admitted } \\
\text { only in } \mathrm{MA} \text { ) }\end{array}$ & $\begin{array}{l}\text { Coded } \\
\text { discharge } \\
\text { with } \\
\text { COVID-19 } \\
\end{array}$ & $\begin{array}{l}\text { Age, sex, race, } \\
\text { comorbidity }\end{array}$ & $\begin{array}{l}\text { CC } n=747 \\
m I V \\
n=172\end{array}$ & $\begin{array}{l}\text { Non-severe vs } \\
\text { severe }\end{array}$ & $\begin{array}{l}747 \\
(31 \%)\end{array}$ & uk & 1 \\
\hline \multicolumn{11}{|l|}{ PIMS-TS / MIS-C } \\
\hline $\begin{array}{l}\text { Abdel-Haq(67), Jan } \\
\text { 2021, USA }\end{array}$ & $\begin{array}{l}\text { Retrospective } \\
\text { observational }\end{array}$ & 33 & $\begin{array}{l}<18 \text { years } \\
\text { Hospitalised }\end{array}$ & $\begin{array}{l}\text { MIS-C } \\
\text { (CDC) }\end{array}$ & $\begin{array}{l}\text { Comorbidity } \\
\text { Obesity not } \\
\text { defined }\end{array}$ & CC $n=22$ & $\begin{array}{l}\text { Admission to critical } \\
\text { care }\end{array}$ & $\begin{array}{l}22 \\
(67 \%)\end{array}$ & Uk & 1 \\
\hline $\begin{array}{l}\text { Capone (68), June } \\
\text { 2020, USA }\end{array}$ & $\begin{array}{l}\text { Retrospective } \\
\text { observational }\end{array}$ & 33 & $\begin{array}{l}\text { Hospitalised } \\
<18 \text { years } \\
\end{array}$ & $\begin{array}{l}\text { MIS-C } \\
\text { (CDC) } \\
\end{array}$ & Sex & $\begin{array}{l}\text { Death } \\
\mathrm{n}=0\end{array}$ & None & $\begin{array}{l}26 \\
(79 \%) \\
\end{array}$ & 0 & 1 \\
\hline $\begin{array}{l}\text { Crawford(69), Feb } \\
\text { 2021, USA }\end{array}$ & $\begin{array}{l}\text { Retrospective } \\
\text { observational }\end{array}$ & 5 & $\begin{array}{l}<19 \text { years } \\
\text { Hospitalised }\end{array}$ & $\begin{array}{l}\text { MIS-C } \\
\text { (CDC) }\end{array}$ & $\begin{array}{l}\text { Sex, } \\
\text { comorbidity, } \\
\text { age } \\
\text { Obesity not } \\
\text { defined }\end{array}$ & $\begin{array}{l}\text { CC } n=4 \\
\text { mIV } n=0 \\
\text { CVS } n=5 \\
\text { Death } \\
n=0\end{array}$ & None & $\begin{array}{l}4 \\
(80 \%)\end{array}$ & 0 & $\$$ \\
\hline $\begin{array}{l}\text { Dufort(70), June } \\
\text { 2020, USA }\end{array}$ & $\begin{array}{l}\text { Emergency } \\
\text { state } \\
\text { reporting } \\
\text { system }\end{array}$ & 99 & $\begin{array}{l}<21 \text { years } \\
\text { Hospitalised }\end{array}$ & $\begin{array}{l}\text { MIS-C } \\
\text { (NYSDOH) }\end{array}$ & Age & $\begin{array}{l}\text { CC } n=79 \\
\text { mIV n=10 } \\
\text { CVS } n=61 \\
\text { Death } \\
n=2\end{array}$ & $\begin{array}{l}\text { Clinical features and } \\
\text { outcomes compared } \\
\text { by age }\end{array}$ & $\begin{array}{l}79 \\
(80 \%)\end{array}$ & $\begin{array}{l}2 \\
(2 \%)\end{array}$ & 1 \\
\hline $\begin{array}{l}\text { Riollano-Cruz(71), } \\
\text { USA }\end{array}$ & $\begin{array}{l}\text { Retrospective } \\
\text { cohort }\end{array}$ & 15 & $\begin{array}{l}\text { Patients } \\
\text { admitted to } \\
\text { hospital } \\
<21 \text { years }\end{array}$ & $\begin{array}{l}\text { MIS-C } \\
\text { (CDC) }\end{array}$ & $\begin{array}{l}\text { Sex, } \\
\text { comorbidity, } \\
\text { age, Race }\end{array}$ & $\begin{array}{l}\text { CC } \mathrm{n}=1 \\
\mathrm{mIV}, \mathrm{n}=3 \\
\text { CVS } \mathrm{n}=1 \\
\text { Death } \\
\mathrm{n}=1\end{array}$ & None & $\begin{array}{l}1 \\
(6.7 \%)\end{array}$ & $\begin{array}{l}1 \\
(6.7 \%)\end{array}$ & $*$ \\
\hline
\end{tabular}




\begin{tabular}{|c|c|c|c|c|c|c|c|c|c|c|}
\hline \multicolumn{2}{|l|}{ Study } & \multicolumn{2}{|l|}{ Population } & \multirow{2}{*}{$\begin{array}{l}\text { Exposure } \\
\text { MIS-C } \\
\text { (CDC) }\end{array}$} & \multirow{2}{*}{$\begin{array}{l}\text { Risk Factors } \\
\text { used in MA } \\
\text { Age, race, sex }\end{array}$} & \multirow{2}{*}{$\begin{array}{l}\text { Outcomes } \\
\text { used in } \\
\text { MA } \\
\text { CC } n=12 \\
\text { mIV n=5 } \\
\text { Death } \\
n=1\end{array}$} & \multirow{2}{*}{$\begin{array}{l}\text { Comparator } \\
\text { Group(s) } \\
\text { COVID-19 cohort } \\
\text { compared to MIS-C } \\
\text { cohort (with and } \\
\text { without } \\
\text { mucocutaneous } \\
\text { disease) }\end{array}$} & \multirow{2}{*}{$\begin{array}{l}\mathrm{CC} \\
\mathrm{n}(\%) \\
12 \\
(63 \%)\end{array}$} & \multirow{2}{*}{$\begin{array}{l}\text { Death } \\
\mathrm{n}(\%) \\
1 \\
(5.3 \%)\end{array}$} & \multirow{2}{*}{$\begin{array}{l}\text { Data } \\
\text { Source } \\
*\end{array}$} \\
\hline $\begin{array}{l}\text { Rekhtman(72), Feb } \\
\text { 2021, USA }\end{array}$ & $\begin{array}{l}\text { Prospective } \\
\text { observational }\end{array}$ & 19 & $\begin{array}{l}\text { Hospitalised } \\
<16 \text { years }\end{array}$ & & & & & & & \\
\hline $\begin{array}{l}\text { Abrams (74), May } \\
\text { 2021, USA }\end{array}$ & $\begin{array}{l}\text { Retrospective } \\
\text { surveillance } \\
\text { study }\end{array}$ & 1080 & $\begin{array}{l}\text { Hospitilised } \\
<22 \text { years }\end{array}$ & $\begin{array}{l}\text { MIS-C } \\
(\mathrm{CDC})\end{array}$ & $\begin{array}{l}\text { Sex, } \\
\text { comorbidity, } \\
\text { Age, Race } \\
\text { Obesity either } \\
\text { documented } \\
\text { by physician } \\
\text { or BMI } 95^{\text {th }} \\
\text { percentile for } \\
\text { age and sex }\end{array}$ & $\mathrm{CC}$ & $\begin{array}{l}\text { Admission to ICU vs } \\
\text { no ICU }\end{array}$ & $\begin{array}{l}648 \\
(60 \%)\end{array}$ & $\begin{array}{l}18 \\
(2 \%)\end{array}$ & 1 \\
\hline \multicolumn{11}{|l|}{ South America } \\
\hline \multicolumn{11}{|l|}{ COVID-19 } \\
\hline $\begin{array}{l}\text { OY Antunez- } \\
\text { Montes(9), Jan } \\
\text { 2021, Latin } \\
\text { America }\end{array}$ & $\begin{array}{l}\text { Prospective } \\
\text { cohort }\end{array}$ & $\begin{array}{l}96 \text { - C-19 } \\
67 \text { - MIS-C }\end{array}$ & $\begin{array}{l}18 \text { years } \\
\text { All patients } \\
\text { attending ED }\end{array}$ & $\begin{array}{l}\text { RT-PCR } \\
\text { pos } \\
\text { MIS-C } \\
\text { (CDC) }\end{array}$ & $\begin{array}{l}\text { Sex, } \\
\text { comorbidity, } \\
\text { age, } \\
\text { socioeconomic } \\
\text { status, viral } \\
\text { co-infections } \\
\end{array}$ & $\begin{array}{l}\text { CC } n=43 \\
\text { mIV n=23 } \\
\text { Death } \\
n=16\end{array}$ & $\begin{array}{l}\text { Admission to } \\
\text { hospital, admission } \\
\text { to PICU }\end{array}$ & $\begin{array}{l}43 \\
(26 \%)\end{array}$ & $\begin{array}{l}16 \\
(10 \%)\end{array}$ & 1 \\
\hline $\begin{array}{l}\text { Araujo da } \\
\text { Silva(75), Jan } \\
\text { 2021, Brazil }\end{array}$ & $\begin{array}{l}\text { Retrospective } \\
\text { cohort }\end{array}$ & $\begin{array}{l}50 \text { - C-19 } \\
14 \text { - MIS-C }\end{array}$ & $\begin{array}{l}\text { Patients } \\
\text { admitted to } \\
\text { hospital. } \\
\text { Clinical } \\
\text { symptoms } \\
\text { consistent } \\
\text { with COVID- } \\
19 . \\
\end{array}$ & $\begin{array}{l}\text { RT-PCR } \\
\text { pos } \\
\text { MIS-C } \\
\text { (WHO) }\end{array}$ & $\begin{array}{l}\text { Age, gender, } \\
\text { comorbidity } \\
\text { Obesity not } \\
\text { defined }\end{array}$ & CC $n=38$ & $\begin{array}{l}\text { Predominant vs non- } \\
\text { predominant } \\
\text { respiratory } \\
\text { symptoms }\end{array}$ & $\begin{array}{l}38 \\
(59 \%)\end{array}$ & $\begin{array}{l}1 \\
(1.6 \%)\end{array}$ & * \\
\hline $\begin{array}{l}\text { Sousa(19), Oct } \\
\text { 2020, Brazil }\end{array}$ & $\begin{array}{l}\text { Routinely } \\
\text { collected } \\
\text { dataset }\end{array}$ & 6948 & $\begin{array}{l}<20 \text { years, } \\
\text { admission to } \\
\text { hospital, } \\
\text { Severe } \\
\text { acute } \\
\text { respiratory } \\
\text { infection } \\
\text { symptoms } \\
\end{array}$ & $\begin{array}{l}\text { RT-PCR } \\
\text { pos }\end{array}$ & $\begin{array}{l}\text { Sex, } \\
\text { comorbidities, } \\
\text { Age } \\
\text { Obesity not } \\
\text { defined }\end{array}$ & $\begin{array}{l}\text { CC } \\
n=1867 \\
m I V \\
n=755 \\
\text { Death } \\
n=564\end{array}$ & $\begin{array}{l}\text { Outcomes of SARS- } \\
\text { CoV-2 with other } \\
\text { viral illnesses } \\
\text { including influenza. }\end{array}$ & $\begin{array}{l}1867 \\
(27 \%)\end{array}$ & $\begin{array}{l}564 \\
(8.1 \%)\end{array}$ & $* *$ \\
\hline $\begin{array}{l}\text { Hillesheim(76), } \\
\text { Oct 2020, Brazil }\end{array}$ & $\begin{array}{l}\text { Prospective } \\
\text { reporting to } \\
\text { national } \\
\text { surveillance } \\
\text { system }\end{array}$ & 6989 & $\begin{array}{l}<20 \text { years } \\
\text { Admitted } \\
\text { Excluded if } \\
\text { incomplete } \\
\text { information }\end{array}$ & & $\begin{array}{l}\text { Age, ethnicity, } \\
\text { sex }\end{array}$ & $\begin{array}{l}\mathrm{mIV} \\
\mathrm{n}=610 \\
\text { Death } \\
\mathrm{n}=661\end{array}$ & Survival vs death & $\begin{array}{l}610 \\
(8.7 \%)\end{array}$ & $\begin{array}{l}661 \\
(9.5 \%)\end{array}$ & 1 \\
\hline $\begin{array}{l}\text { Bolanos- } \\
\text { Almeida(77), Jan } \\
\text { 2021, Colombia } \\
\end{array}$ & $\begin{array}{l}\text { Retrospective } \\
\text { Observational }\end{array}$ & 597 & $<18$ years & $\begin{array}{l}\text { RT-PCR } \\
\text { pos }\end{array}$ & Age, Sex & $\begin{array}{l}\text { CC } n=17 \\
\text { Death } \\
n=5\end{array}$ & $\begin{array}{l}\text { Mild, moderate and } \\
\text { severe disease and } \\
\text { death }\end{array}$ & $\begin{array}{l}17 \\
(2.8 \%)\end{array}$ & $\begin{array}{l}5 \\
(0.8 \%)\end{array}$ & * \\
\hline $\begin{array}{l}\text { Cairoli(78), Aug } \\
\text { 2020, Argentina }\end{array}$ & $\begin{array}{l}\text { Retrospective } \\
\text { Observational }\end{array}$ & 578 & $<21$ years & $\begin{array}{l}\text { RT-PCR } \\
\text { pos }\end{array}$ & $\begin{array}{l}\text { Age, sex, } \\
\text { comorbidity } \\
\text { Obesity: not } \\
\text { defined }\end{array}$ & $\begin{array}{l}\text { CC } n=3 \\
\text { mIV } n=1 \\
\text { CVS } n=3 \\
\text { Death } \\
n=1\end{array}$ & None & $\begin{array}{l}3 \\
(0.5 \%)\end{array}$ & $\begin{array}{l}1 \\
(0.2 \%)\end{array}$ & * \\
\hline $\begin{array}{l}\text { Sena(79), Feb } \\
\text { 2021, Brazil }\end{array}$ & $\begin{array}{l}\text { National } \\
\text { Registry }\end{array}$ & 315 & $<20$ years & $\begin{array}{l}\text { RT-PCR } \\
\text { pos }\end{array}$ & Age & $\begin{array}{l}\text { Death } \\
\mathrm{n}=38\end{array}$ & $\begin{array}{l}\text { Outcomes compared } \\
\text { by age and co- } \\
\text { morbidity } \\
\text { (hospitalised and } \\
\text { community). }\end{array}$ & & $\begin{array}{l}38 \\
(5.6 \%)\end{array}$ & 1 \\
\hline \multicolumn{11}{|l|}{ PIMS-TS / MIS-C } \\
\hline $\begin{array}{l}\text { Torres(80), Aug } \\
\text { 2020, Chile }\end{array}$ & $\begin{array}{l}\text { Retrospective } \\
\text { and } \\
\text { prospective } \\
\text { cohort } \\
\end{array}$ & 27 & $\begin{array}{l}\text { Patients } \\
\text { admitted to } \\
\text { hospital } \\
<15 \text { years }\end{array}$ & $\begin{array}{l}\text { MIS-C } \\
\text { (CDC) }\end{array}$ & Sex & $\mathrm{CC} n=16$ & $\begin{array}{l}\text { Ward vs critical care } \\
\text { admission }\end{array}$ & $\begin{array}{l}16 \\
(59 \%)\end{array}$ & 0 & I \\
\hline $\begin{array}{l}\text { Luna-Muñoz, 2021, } \\
\text { Peru }\end{array}$ & $\begin{array}{l}\text { Retrospective } \\
\text { cohort }\end{array}$ & 10 & $\begin{array}{l}<13 \text { years } \\
\text { Hospitalised }\end{array}$ & $\begin{array}{l}\text { MIS-C } \\
(\mathrm{CDC})\end{array}$ & $\begin{array}{l}\text { Age, Sex, co- } \\
\text { morbidity }\end{array}$ & $\begin{array}{l}\mathrm{mIV} n=3 \\
\text { Death } \\
\mathrm{n}=0\end{array}$ & None & uk & 0 & 1 \\
\hline $\begin{array}{l}\text { Clark(81), Sept } \\
\text { 2020, Global }\end{array}$ & $\begin{array}{l}\text { Retrospective } \\
\text { observational }\end{array}$ & 55 & $\begin{array}{l}<19 \text { years } \\
\text { Hospitalised }\end{array}$ & $\begin{array}{l}\text { MIS-C } \\
(\mathrm{WHO})\end{array}$ & Age, ethnicity & $\mathrm{CC} n=27$ & $\begin{array}{l}\text { Comparison of } \\
\text { cardiac } \\
\text { abnormalities } \\
\end{array}$ & $\begin{array}{l}27 \\
(49 \%)\end{array}$ & $\begin{array}{l}2 \\
(3.6 \%)\end{array}$ & $\$$ \\
\hline
\end{tabular}

Table 2. Study characteristics of comorbidity studies for CYP with COVID-19 and PIMS-TS or MIS-C. Admission to critical care - CC. 


\begin{tabular}{|c|c|c|c|c|c|c|c|c|}
\hline \multicolumn{2}{|l|}{ Study } & \multicolumn{2}{|c|}{ Population } & \multirow{2}{*}{\begin{tabular}{|l|} 
Exposure \\
Criteria \\
for \\
diagnosis \\
\end{tabular}} & \multirow[t]{2}{*}{$\begin{array}{l}\text { Comparator } \\
\text { Group(s) }\end{array}$} & \multirow[t]{2}{*}{$\begin{array}{l}\mathrm{CC} \\
\mathrm{n}(\%)\end{array}$} & \multirow[t]{2}{*}{$\begin{array}{l}\text { Death } \\
\mathrm{n}(\%)\end{array}$} & \multirow[t]{2}{*}{ Other } \\
\hline $\begin{array}{l}\text { Author, Date, } \\
\text { Country }\end{array}$ & Study Design & $\begin{array}{l}\text { No of } \\
\text { admitted } \\
\text { children }\end{array}$ & $\begin{array}{l}\text { Inclusion and } \\
\text { Exclusion criteria }\end{array}$ & & & & & \\
\hline \multicolumn{9}{|l|}{ Cystic Fibrosis } \\
\hline \multicolumn{9}{|l|}{ COVID-19 } \\
\hline $\begin{array}{l}\text { Bain(82), Dec 2020, } \\
\text { Europe }\end{array}$ & $\begin{array}{l}\text { Retrospective and } \\
\text { prospective registry }\end{array}$ & 24 & $<18$ years & $\begin{array}{l}\text { RT-PCR } \\
\text { pos or } \\
\text { clinical } \\
\text { diagnosis } \\
\end{array}$ & None & $\begin{array}{l}1 \\
(4.2 \%)\end{array}$ & 0 & \\
\hline \multicolumn{9}{|l|}{ Heart Disease } \\
\hline \multicolumn{9}{|l|}{ COVID-19 } \\
\hline $\begin{array}{l}\text { Simpson(83), July } \\
\text { 2020, USA }\end{array}$ & Case Series & 7 & $<20$ years & $\begin{array}{l}\text { RT-PCR } \\
\text { pos }\end{array}$ & None & $\begin{array}{l}3 \\
(43 \%)\end{array}$ & $\begin{array}{l}1 \\
(14 \%)\end{array}$ & $\begin{array}{l}\text { Atrioventricular Septal Defect } \\
\text { (AVSD) ( }=2 \text { ) } \\
\text { Anomalous left coronary } \\
\text { artery from pulmonary artery } \\
(n=1) \\
\text { Tetralogy of fallot ( } n=1) \\
\text { Hypertrophic cardiomyopathy } \\
\text { (n=1) } \\
\text { Dilated cardiomyopathy }(n=1) \\
\text { Cardiac transplant }(n=1) \\
\text { Comorbidities: Trisomy } 21 \\
(n=3) \text {, Obesity }(n=2) \text {, } \\
\text { Diabetes }(n=1), \text { Chronic } \\
\text { Kidney Disease }(n=1), \\
\text { Asthma }(n=1)\end{array}$ \\
\hline $\begin{array}{l}\text { Esmaeeli(84), April } \\
\text { 2021, Iran }\end{array}$ & Case Series & 7 & $\begin{array}{l}<19 \text { years } \\
\text { Hospitalised }\end{array}$ & $\begin{array}{l}\text { RT-PCR } \\
\text { pos }\end{array}$ & None & $\begin{array}{l}5 \\
(71 \%)\end{array}$ & $\begin{array}{l}2 \\
(29 \%)\end{array}$ & $\begin{array}{l}\text { Hypoplastic Left Heart }(\mathrm{n}=1) \\
\text { Truncus Arteriosus }(\mathrm{n}=1) \\
\text { Aortic Regurgitation }(\mathrm{n}=1) \\
\text { Ventricular Septal Defect } \\
(\mathrm{n}=1) \\
\text { AVSD }(\mathrm{n}=1) \\
\text { Pulmonary Atresia }(\mathrm{n}=1) \\
\text { Unknown }(\mathrm{n}=1)\end{array}$ \\
\hline \multicolumn{9}{|c|}{ Cancer $+/$ - stem cell transplant } \\
\hline \multicolumn{9}{|c|}{ COVID-19 } \\
\hline $\begin{array}{l}\text { Bisogno(85), July } \\
\text { 2020, Italy }\end{array}$ & $\begin{array}{l}\text { Retrospective and } \\
\text { prospective case } \\
\text { series }\end{array}$ & 15 & $<18$ years & $\begin{array}{l}\text { RT-PCR } \\
\text { pos }\end{array}$ & None & 0 & 0 & \\
\hline $\begin{array}{l}\text { De Rojas(86), April } \\
\text { 2020, Spain }\end{array}$ & $\begin{array}{l}\text { Retrospective case } \\
\text { series }\end{array}$ & 11 & $<19$ years & $\begin{array}{l}\text { RT-PCR } \\
\text { pos }\end{array}$ & None & 0 & 0 & $\begin{array}{l}\text { Leukaemia }(n=8) \\
\text { Lymphoma }(n=1) \\
\text { Bone / soft tissue }(n=1) \\
\text { Solid organ }(n=1)\end{array}$ \\
\hline $\begin{array}{l}\text { Ebeid(87), Dec } \\
\text { 2020, Egypt }\end{array}$ & $\begin{array}{l}\text { Prospective } \\
\text { observational study }\end{array}$ & 15 & $\mathrm{u} / \mathrm{k}$ & $\begin{array}{l}\text { RT-PCR } \\
\text { pos }\end{array}$ & None & 0 & $\begin{array}{l}2 \\
(13 \%)\end{array}$ & $\begin{array}{l}\text { Leukaemia }(\mathrm{n}=12) \\
\text { Lymphoma }(\mathrm{n}=1) \\
\text { Other }(\mathrm{n}=2) \\
5 \text { symptomatic, } 10 \\
\text { asymptomatic } \\
\text { Deaths not due to COVID-19 }\end{array}$ \\
\hline $\begin{array}{l}\text { Ferrari(88), April } \\
\text { 2020, Italy }\end{array}$ & $\begin{array}{l}\text { Retrospective and } \\
\text { prospective case } \\
\text { series }\end{array}$ & 21 & $<18$ years & $\begin{array}{l}\text { RT-PCR } \\
\text { pos }\end{array}$ & None & $\mathrm{u} / \mathrm{k}$ & 0 & $\begin{array}{l}\text { Leukaemia }(n=10) \\
\text { Lymphoma }(n=2) \\
\text { Other }(n=9)\end{array}$ \\
\hline $\begin{array}{l}\text { Gampel(89), June } \\
\text { 2020, USA }\end{array}$ & $\begin{array}{l}\text { Retrospective } \\
\text { observational study }\end{array}$ & 11 & $<18$ years & $\begin{array}{l}\text { RT-PCR } \\
\text { pos }\end{array}$ & None & $\begin{array}{l}5 \\
(45 \%)\end{array}$ & 0 & $\begin{array}{l}\text { Inpatient and outpatient } \\
\text { Leukaemia/Lymphoma }(\mathrm{n}=6) \\
\text { Solid Tumour }(\mathrm{n}=8) \\
\text { Haematological diagnosis } \\
(\mathrm{n}=3) \\
\text { Hematopoietic stem cell } \\
\text { transplant }(\mathrm{n}=2)\end{array}$ \\
\hline $\begin{array}{l}\text { Millen(90), Nov } \\
\text { 2020, UK }\end{array}$ & $\begin{array}{l}\text { Retrospective and } \\
\text { prospective } \\
\text { observational study }\end{array}$ & 40 & $<16$ years & $\begin{array}{l}\text { RT-PCR } \\
\text { pos }\end{array}$ & None & $\begin{array}{l}3 \\
(8 \%)\end{array}$ & $\begin{array}{l}1 \\
(3 \%)\end{array}$ & $\begin{array}{l}\text { Inpatient and outpatient } \\
\text { Leukaemia }(n=28) \\
\text { Lymphoma }(n=2) \\
\text { Soft tissue tumour }(n=4) \\
\text { Solid organ tumour }(n=10) \\
\text { CNS tumour }(n=5) \\
\text { Other }(n=5) \\
11 / 40(28 \%) \text { nosocomial } \\
\text { infection } \\
\text { Death not due to COVID-19 }\end{array}$ \\
\hline $\begin{array}{l}\text { Montoya(31), July } \\
\text { 2020, Peru }\end{array}$ & Case Series & 33 & $<17$ years & $\begin{array}{l}\text { RT-PCR } \\
\text { pos }\end{array}$ & None & $\begin{array}{l}3 \\
(9 \%)\end{array}$ & $\begin{array}{l}7 \\
(21 \%)\end{array}$ & $\begin{array}{l}\text { Inpatient and outpatient } \\
\text { Leukaemia }(n=39) \\
\text { Lymphoma }(n=5) \\
\text { CNS tumour }(n=5) \\
\text { Other }(n=27) \\
20 / 33(61 \%) \text { due to } \\
\text { nosocomial infection } \\
4 / 7(57 \%) \text { deaths not due to } \\
\text { COVID-19 }\end{array}$ \\
\hline
\end{tabular}




\begin{tabular}{|c|c|c|c|c|c|c|c|c|}
\hline \multicolumn{2}{|l|}{ Study } & \multicolumn{2}{|c|}{ Population } & \multirow{2}{*}{$\begin{array}{l}\text { Exposure } \\
\text { RT-PCR } \\
\text { pos }\end{array}$} & \multirow{2}{*}{$\begin{array}{l}\text { Comparator } \\
\text { Group(s) } \\
\text { None }\end{array}$} & \multirow{2}{*}{$\begin{array}{l}\mathrm{CC} \\
\mathrm{n}(\%) \\
2 \\
(7 \%)\end{array}$} & \multirow{2}{*}{$\begin{array}{l}\begin{array}{l}\text { Death } \\
\mathrm{n}(\%)\end{array} \\
3 \\
(10 \%)\end{array}$} & \multirow{2}{*}{$\begin{array}{l}\text { Other } \\
\text { Inpatient and Outpatient } \\
\text { Leukaemia }(n=24) \\
\text { Other }(\mathrm{n}=14) \\
\text { All deaths due to underlying } \\
\text { condition }\end{array}$} \\
\hline $\begin{array}{l}\text { Palomo Colli(91), } \\
\text { Dec 2020, Mexico }\end{array}$ & Case Series & 30 & $<18$ years & & & & & \\
\hline $\begin{array}{l}\text { Radhakrishna(92), } \\
\text { Sept 2020, India }\end{array}$ & Case Series & 16 & $<18$ years & $\begin{array}{l}\text { RT-PCR } \\
\text { pos }\end{array}$ & None & $\begin{array}{l}1 \\
(6 \%)\end{array}$ & 0 & $\begin{array}{l}\text { Leukaemia }(\mathrm{n}=12) \\
\text { Other }(\mathrm{n}=3) \\
15 / 16(94 \%) \text { nosocominal } \\
\text { infections }\end{array}$ \\
\hline $\begin{array}{l}\text { Sanchez-Jara(93), } \\
\text { Nov 2020, Mexico }\end{array}$ & $\begin{array}{l}\text { Retrospective } \\
\text { observational study }\end{array}$ & 15 & $<16$ years & $\begin{array}{l}\text { RT-PCR } \\
\text { pos }\end{array}$ & None & $\mathrm{u} / \mathrm{k}$ & $\begin{array}{l}7 \\
(47 \%)\end{array}$ & Leukaemia (n=15) \\
\hline $\begin{array}{l}\text { Madhusoodhan(94), } \\
\text { April 2020, USA }\end{array}$ & $\begin{array}{l}\text { Retrospective } \\
\text { cohort study }\end{array}$ & 28 & $<22$ years & $\begin{array}{l}\text { RT-PCR } \\
\text { pos }\end{array}$ & None & $\mathrm{u} / \mathrm{k}$ & $\begin{array}{l}4 \\
(14 \%)\end{array}$ & $\begin{array}{l}\text { Inpatient and Outpatient } \\
\text { Leukaemia }(\mathrm{n}=61) \\
\text { Lymphoma }(\mathrm{n}=3) \\
\text { Other }(\mathrm{n}=34) \\
\text { No deaths solely due to } \\
\text { COVID-19 }\end{array}$ \\
\hline $\begin{array}{l}\text { Kebudi(95), Jan } \\
\text { 2021, Turkey }\end{array}$ & $\begin{array}{l}\text { Retrospective cross- } \\
\text { sectional study }\end{array}$ & 38 & $<18$ years & $\begin{array}{l}\text { RT-PCR } \\
\text { pos }\end{array}$ & None & $\begin{array}{l}9 \\
(24 \%)\end{array}$ & $\begin{array}{l}1 \\
(3 \%)\end{array}$ & $\begin{array}{l}\text { Inpatient and Outpatient } \\
\text { Leukaemia }(n=26) \\
\text { Lymphoma }(n=5) \\
\text { Other }(n=20) \\
\text { No deaths solely due to } \\
\text { COVID-19 }\end{array}$ \\
\hline $\begin{array}{l}\text { Lima(96), Nov } \\
\text { 2020, Brazil }\end{array}$ & $\begin{array}{l}\text { Retrospective } \\
\text { cohort study }\end{array}$ & 35 & $<19$ years & $\begin{array}{l}\text { RT-PCR } \\
\text { pos }\end{array}$ & None & $\begin{array}{l}10 \\
(29 \%)\end{array}$ & $\begin{array}{l}8 \\
(23 \%)\end{array}$ & $\begin{array}{l}5 \text { deaths within } 30 \text { days, } 8 \\
\text { within } 60 \text { days }\end{array}$ \\
\hline $\begin{array}{l}\text { Fonseca (97), Feb } \\
\text { 2021, Colombia }\end{array}$ & $\begin{array}{l}\text { Observational } \\
\text { retrospective study }\end{array}$ & 33 & $<18$ years & $\begin{array}{l}\text { RT-PCR } \\
\text { pos }\end{array}$ & $\begin{array}{l}\text { Comparison of } \\
\text { diagnoses and } \\
\text { admission to CC }\end{array}$ & $\begin{array}{l}7 \\
(21 \%)\end{array}$ & $\begin{array}{l}5 \\
(15 \%)\end{array}$ & $\begin{array}{l}2 \text { deaths due to COVID-19 } \\
\text { Leukaemia ( } \mathrm{n}=14,5 \text { admitted } \\
\text { CC) } \\
\text { Lymphoma ( } \mathrm{n}=4,1 \text { admitted } \\
\text { CC) } \\
\text { Other ( } \mathrm{n}=9,1 \text { admitted CC) }\end{array}$ \\
\hline $\begin{array}{l}\text { Vincet(98), June } \\
\text { 2020, Spain }\end{array}$ & $\begin{array}{l}\text { Retrospective case } \\
\text { series }\end{array}$ & 5 & $<13$ years & $\begin{array}{l}\text { RT-PCR } \\
\text { pos }\end{array}$ & None & $\begin{array}{l}2 \\
(40 \%)\end{array}$ & $\begin{array}{l}1 \\
(20 \%)\end{array}$ & $\begin{array}{l}3 / 5(60 \%) \text { nosocomial } \\
\text { infections }\end{array}$ \\
\hline \multicolumn{9}{|l|}{ Haematological } \\
\hline \multicolumn{9}{|l|}{ COVID-19 } \\
\hline $\begin{array}{l}\text { Arlet(99), June } \\
\text { 2020, France }\end{array}$ & $\begin{array}{l}\text { Prospective case } \\
\text { series }\end{array}$ & 12 & $<15$ years & $\begin{array}{l}\text { RT-PCR } \\
\text { pos }\end{array}$ & $\begin{array}{l}\text { Compared by } \\
\text { age }\end{array}$ & $\begin{array}{l}2 \\
(17 \%)\end{array}$ & 0 & Sickle Cell Disease \\
\hline $\begin{array}{l}\text { Telfer(100), Nov } \\
\text { 2020, England }\end{array}$ & $\begin{array}{l}\text { Prospective case } \\
\text { series }\end{array}$ & 10 & $<20$ years & $\begin{array}{l}\text { RT-PCR } \\
\text { pos }\end{array}$ & $\begin{array}{l}\text { Compared by } \\
\text { age }\end{array}$ & uk & $\begin{array}{l}1 \\
(10 \%)\end{array}$ & Sickle Cell Disease \\
\hline \multicolumn{9}{|l|}{ Immunosuppression } \\
\hline \multicolumn{9}{|l|}{ COVID-19 } \\
\hline $\begin{array}{l}\text { Dannan(101), Oct } \\
\text { 2020, United Arab } \\
\text { Emirates }\end{array}$ & Case Series & 5 & $<13$ years & $\begin{array}{l}\text { RT-PCR } \\
\text { pos }\end{array}$ & None & 0 & 0 & $\begin{array}{l}\text { Common Variable } \\
\text { Immunodeficiency }(\mathrm{n}=1) \\
\text { Chemotherapy }(\mathrm{n}=1) \\
\text { Pyruvate kinase deficiency } \\
\text { and splenectomy }(\mathrm{n}=1) \\
\text { Nephrotic Syndrome on } \\
\text { Prednisione }(\mathrm{n}=1) \\
\text { Systemic Lupus } \\
\text { Erythematosus on } \\
\text { Prednisiolone and } \\
\text { Mycofenolate }(\mathrm{n}=1) \\
\end{array}$ \\
\hline $\begin{array}{l}\text { Perez- } \\
\text { Martinez(102), } \\
\text { August 2020, Spain }\end{array}$ & $\begin{array}{l}\text { Retrospective case } \\
\text { series }\end{array}$ & 5 & $<15$ years & $\begin{array}{l}\text { RT-PCR } \\
\text { pos }\end{array}$ & None & 0 & 0 & $\begin{array}{l}\text { Hematopoietic stem cell } \\
\text { transplant }(\mathrm{n}=1) \\
\text { Leukaemia }(\mathrm{n}=1) \\
\text { Liver Transplant }(\mathrm{n}=1) \\
\text { Kidney Transplant }(\mathrm{n}=1) \\
\text { C-ANCA vasculitis }(\mathrm{n}=1) \\
\end{array}$ \\
\hline \multicolumn{9}{|c|}{ Chronic Kidney Disease } \\
\hline \multicolumn{9}{|l|}{ COVID-19 } \\
\hline $\begin{array}{l}\text { Melgosa(103), May } \\
\text { 2020, Spain }\end{array}$ & $\begin{array}{l}\text { Retrospective case } \\
\text { series }\end{array}$ & 8 & $<18$ years & $\begin{array}{l}\text { RT-PCR } \\
\text { pos }\end{array}$ & None & 0 & 0 & $\begin{array}{l}\text { Inpatient and Outpatient } \\
\text { Renal Dysplasia }(n=5) \\
\text { Nephrotic Syndrome }(n=5) \\
\text { Uropathy }(n=2) \\
\text { Other }(n=4)\end{array}$ \\
\hline $\begin{array}{l}\text { Malaris (104), Nov } \\
\text { 2020, Global }\end{array}$ & $\begin{array}{l}\text { Retrospective and } \\
\text { prospective } \\
\text { observational study }\end{array}$ & 68 & $\begin{array}{l}<20 \text { years } \\
\text { Under Paediatric } \\
\text { Services } \\
\text { CKD on } \\
\text { immunosuppression } \\
\end{array}$ & $\begin{array}{l}\text { RT-PCR } \\
\text { pos }\end{array}$ & None & $\begin{array}{l}6 \\
(9 \%)\end{array}$ & $\begin{array}{l}4 \\
(6 \%)\end{array}$ & $\begin{array}{l}\text { Inpatient and Outpatient } \\
\text { Kidney transplantation } \\
(\mathrm{n}=53) \\
\text { Nephrotic Syndrome }(\mathrm{n}=30) \\
\text { Other }(\mathrm{n}=30)\end{array}$ \\
\hline \multicolumn{9}{|l|}{ Rheumatic Diseases } \\
\hline \multicolumn{9}{|l|}{ COVID-19 } \\
\hline $\begin{array}{l}\text { Villacis- } \\
\text { Nunez(105), Jan } \\
\text { 2021, USA }\end{array}$ & $\begin{array}{l}\text { Retrospective case } \\
\text { series }\end{array}$ & 8 & $<22$ years & $\begin{array}{l}\text { RT-PCR } \\
\text { pos }\end{array}$ & $\begin{array}{l}\text { Need for } \\
\text { hospitalisation }\end{array}$ & $\begin{array}{l}3 \\
(38 \%)\end{array}$ & 0 & $\begin{array}{l}\text { Juvenile Idiopathic Arthritis } \\
(\mathrm{n}=1) \\
\text { Systemic Lupus } \\
\text { Erythematosis }(\mathrm{n}=5) \\
\text { Other }(\mathrm{n}=2)\end{array}$ \\
\hline
\end{tabular}




\begin{tabular}{|c|c|c|c|c|c|c|c|c|}
\hline \multicolumn{2}{|l|}{ Study } & \multicolumn{2}{|c|}{ Population } & Exposure & \begin{tabular}{|l} 
Comparator \\
Group(s)
\end{tabular} & \begin{tabular}{|l|}
$\mathrm{CC}$ \\
$\mathrm{n}(\%)$ \\
\end{tabular} & $\begin{array}{l}\text { Death } \\
\mathrm{n}(\%)\end{array}$ & Other \\
\hline \multicolumn{9}{|c|}{ Liver Disease and transplant } \\
\hline \multicolumn{9}{|l|}{ COVID-19 } \\
\hline $\begin{array}{l}\text { Kehar(106), Feb } \\
\text { 2021, International }\end{array}$ & $\begin{array}{l}\text { Retrospective } \\
\text { observational study }\end{array}$ & 21 & $\begin{array}{l}\text { Community and } \\
\text { hospitalised } \\
<21 \text { years }\end{array}$ & $\begin{array}{l}\text { RT-PCR or } \\
\text { antibody }\end{array}$ & $\begin{array}{l}\text { Native liver } \\
\text { disease vs liver } \\
\text { transplant } \\
\text { recipient } \\
\end{array}$ & $\begin{array}{l}2 \\
(9.5 \%)\end{array}$ & $\begin{array}{l}1 \\
(4.2 \%)\end{array}$ & $\begin{array}{l}\text { Native liver disease }(\mathrm{n}=44) \\
\text { Liver transplant recipient } \\
(\mathrm{n}=47)\end{array}$ \\
\hline
\end{tabular}

\section{References}

1. Davies NG, Klepac P, Liu Y, Prem K, Jit M, group CC-w, et al. Age-dependent effects in the transmission and control of COVID-19 epidemics. Nature Med 2020.

2. Docherty A, Harrison E, Green C, Hardwick H, Pius R, Norman L, et al. Features of 20133 UK patients in hospital with covid-19 using the ISARIC WHO Clinical Characterisation Protocol: prospective observational cohort study. BMJ. 2020.

3. Bhopal SS, Bagaria J, Olabi B, Bhopal R. Children and young people remain at low risk of COVID-19 mortality. Lancet Child Adolesc Health. 2021;5(5):e12-e3.

4. Whittaker E, Bamford A, Kenny J, Kaforou M, Jones CE, Shah P, et al. Clinical Characteristics of 58 Children With a Pediatric Inflammatory Multisystem Syndrome Temporally Associated With SARS-CoV-2. JAMA. 2020;324(3):259-69.

5. Riollano-Cruz M, Akkoyun E, Briceno-Brito E, Kowalsky S, Posada R, Sordillo EM, et al. Multisystem Inflammatory Syndrome in Children (MIS-C) Related to COVID-19: A New York City Experience. J Med Virol. 2020.

6. RCPCH. Guidance: Paediatric multisystem inflammatory syndrome temporally associated with COVID-192020. Available from: https://www.rcpch.ac.uk/sites/default/files/2020-05/COVID-19-Paediatric-multisystem-\%20inflammatory\%20syndrome-20200501.pdf.

7. Swann OV, Holden KA, Turtle L, Pollock L, Fairfield CJ, Drake TM, et al. Clinical characteristics of children and young people admitted to hospital with covid-19 in United Kingdom: prospective multicentre observational cohort study. BMJ. 2020;370:m3249.

8. Götzinger F, Santiago-García B, Noguera-Julián A, Lanaspa M, Lancella L, Calò Carducci FI, et al. COVID-19 in children and adolescents in Europe: a multinational, multicentre cohort study. The Lancet Child \& Adolescent Health. 2020;4(9):653-61.

9. Antunez-Montes OY, Escamilla MI, Figueroa-Uribe AF, Arteaga-Menchaca E, Lavariega-Sarachaga M, Salcedo-Lozada P, et al. COVID-19 and Multisystem Inflammatory Syndrome in Latin American Children: A Multinational Study. Pediatr Infect Dis J. 2021;40(1):e1-e6.

10. Moreira A, Chorath K, Rajasekaran K, Burmeister F, Ahmed M, Moreira A. Demographic predictors of hospitalization and mortality in US children with COVID-19. Eur J Pediatr. 2021;180(5):1659-63.

11. Leeb RT, Price S, Sliwa S, Kimball A, Szucs L, Caruso E, et al. COVID-19 Trends Among School-Aged Children - United States, March 1-September 19, 2020. MMWR Morb Mortal Wkly Rep. 2020;69(39):1410-5.

12. Ludvigsson JF. Systematic review of COVID-19 in children shows milder cases and a better prognosis than adults. Acta Paediatr. 2020;109(6):1088-95.

13. Patel NA. Pediatric COVID-19: Systematic review of the literature. Am J Otolaryngol. 2020;41(5):102573.

14. Stilwell PA, Munro APS, Basatemur E, Talawila Da Camara N, Harwood R, Roland D. Bibliography of published COVID-19 in children literature. Arch Dis Child. 2021.

15. Page MJ, Moher D, Bossuyt PM, Boutron I, Hoffmann TC, Mulrow CD, et al. PRISMA 2020 explanation and elaboration: updated guidance and exemplars for reporting systematic reviews. BMJ. 2021;372:n160.

16. Mehta NS, Mytton OT, Mullins EWS, Fowler TA, Falconer CL, Murphy OB, et al. SARS-CoV-2 (COVID-19): What Do We Know About Children? A Systematic Review. Clinical Infectious Diseases. 2020;71(9):2469-79.

17. Wells G, editor Proceedings of the Third Symposium on Systematic Reviews beyond the Basics. Improving Quality and Impact; The NewcastleOwwawa Scale for Assessing the Quality of non-randomised Studies in Meta-Analysis.2000; Oxford.

18. Collaboration TC. Review Manager. 5.4 ed2020.

19. Sousa BLA, Sampaio-Carneiro M, de Carvalho WB, Silva CA, Ferraro AA. Differences among Severe Cases of Sars-CoV-2, Influenza, and Other Respiratory Viral Infections in Pediatric Patients: Symptoms, Outcomes and Preexisting Comorbidities. Clinics (Sao Paulo). 2020;75:e2273. 
20. Williamson EJ, Walker AJ, Bhaskaran K, Bacon S, Bates C, Morton CE, et al. Factors associated with COVID-19-related death using OpenSAFELY. Nature. 2020;584(7821):430-6.

21. Bhopal SS, Bagaria J, Olabi B, Bhopal R. Children and young people remain at low risk of COVID-19 mortality. The Lancet Child \& Adolescent Health. 2021;5(5):e12-e3.

22. Leidman E, Duca LM, Omura JD, Proia K, Stephens JW, Sauber-Schatz EK. COVID-19 Trends Among Persons Aged 0-24 Years - United States, March 1-December 12, 2020. MMWR Morb Mortal Wkly Rep. 2021;70(3):88-94.

23. Flood J, Shingleton J, Bennett E, Walker B, Amin-Chowdhury Z, Oligbu G, et al. Paediatric multisystem inflammatory syndrome temporally associated with SARS-CoV-2 (PIMS-TS): Prospective, national surveillance, United Kingdom and Ireland, 2020. Lancet Reg Health Eur. $2021 ; 3: 100075$.

24. PICANet. Paediatric Intensive Care Audit Network, Annual Report 2020. 2020.

25. NCMD. Second Annual Report, National Child Mortality Database Programme. 2021.

26. Ancochea J, Izquierdo JL, Soriano JB. Evidence of Gender Differences in the Diagnosis and Management of Coronavirus Disease 2019 Patients: An Analysis of Electronic Health Records Using Natural Language Processing and Machine Learning. J Womens Health (Larchmt). 2021;30(3):393-404.

27. Yates T, Zaccardi F, Islam N, Razieh C, Gillies CL, Lawson CA, et al. Obesity, Ethnicity, and Risk of Critical Care, Mechanical Ventilation, and Mortality in Patients Admitted to Hospital with COVID-19: Analysis of the ISARIC CCP-UK Cohort. Obesity (Silver Spring). 2021.

28. Castro-Rodriguez JA, Forno E. Asthma and COVID-19 in children: A systematic review and call for data. Pediatr Pulmonol. 2020;55(9):2412-8.

29. Dorantes-Acosta E, Avila-Montiel D, Klunder-Klunder M, Juarez-Villegas L, Marquez-Gonzalez H. Survival in pediatric patients with cancer during the COVID-19 pandemic: scoping systematic review. Bol Med Hosp Infant Mex. 2020;77(5):234-41.

30. Clift AK, Coupland CAC, Keogh RH, Diaz-Ordaz K, Williamson E, Harrison EM, et al. Living risk prediction algorithm (QCOVID) for risk of hospital admission and mortality from coronavirus 19 in adults: national derivation and validation cohort study. BMJ. 2020;371:m3731.

31. Montoya J, Ugaz C, Alarcon S, Maradiegue E, Garcia J, Diaz R, et al. COVID-19 in pediatric cancer patients in a resource-limited setting: National data from Peru. Pediatr Blood Cancer. 2021;68(2):e28610.

32. Du H, Dong X, Zhang JJ, Cao YY, Akdis M, Huang PQ, et al. Clinical characteristics of 182 pediatric COVID-19 patients with different severities and allergic status. Allergy. 2021;76(2):510-32.

33. Qian G, Zhang Y, Xu Y, Hu W, Hall IP, Yue J, et al. Reduced inflammatory responses to SARS-CoV-2 infection in children presenting to hospital with COVID-19 in China. medRxiv. 2020.

34. Sung HK, Kim JY, Heo J, Seo H, Jang YS, Kim H, et al. Clinical Course and Outcomes of 3,060 Patients with Coronavirus Disease 2019 in Korea, January-May 2020. J Korean Med Sci. 2020;35(30):e280.

35. Alharbi M, Kazzaz YM, Hameed T, Alqanatish J, Alkhalaf H, Alsadoon A, et al. SARS-CoV-2 infection in children, clinical characteristics, diagnostic findings and therapeutic interventions at a tertiary care center in Riyadh, Saudi Arabia. J Infect Public Health. 2021;14(4):446-53.

36. Bayesheva D, Boranbayeva R, Turdalina B, Fakhradiyev I, Saliev T, Tanabayeva S, et al. COVID-19 in the paediatric population of Kazakhstan. Paediatr Int Child Health. 2021;41(1):76-82.

37. Qian G, Zhang Y, Xu Y, Hu W, Hall IP, Yue J, et al. Reduced inflammatory responses to SARS-CoV-2 infection in children presenting to hospital with COVID-19 in China. EClinicalMedicine. 2021;34:100831.

38. Almoosa ZA, Al Ameer HH, AlKadhem SM, Busaleh F, AlMuhanna FA, Kattih O. Multisystem Inflammatory Syndrome in Children, the Real Disease of COVID-19 in Pediatrics - A Multicenter Case Series From Al-Ahsa, Saudi Arabia. Cureus. 2020;12(10):e11064.

39. Jain S, Sen S, Lakshmivenkateshiah S, Bobhate P, Venkatesh S, Udani S, et al. Multisystem Inflammatory Syndrome in Children With COVID-19 in Mumbai, India. Indian Pediatrics. 2020;57(11):1015-9.

40. Shahbaznejad L, Navaeifar MR, Abbaskhanian A, Hosseinzadeh F, Rahimzadeh G, Rezai MS. Clinical characteristics of 10 children with a pediatric inflammatory multisystem syndrome associated with COVID-19 in Iran. BMC Pediatr. 2020;20(1):513.

41. Hasan M, Zubaidi KA, Diab K, Hejazi Y, Bout-Tabaku S, Al-Adba B, et al. COVID-19 related multisystem inflammatory syndrome in children (MIS-C): a case series from a tertiary care pediatic hospital in Qatar. BMC Pediatrics. 2020;In Review.

42. Armann JP, Diffloth N, Simon A, Doenhardt M, Hufnagel M, Trotter A, et al. Hospital Admission in Children and Adolescents With CoVID-19. Dtsch Arztebl Int. 2020;117(21):373-4. 
43. Bellino S, Punzo O, Rota MC, Del Manso M, Urdiales AM, Andrianou X, et al. COVID-19 Disease Severity Risk Factors for Pediatric Patients in Italy. Pediatrics. 2020;146(4).

44. Giacomet V, Barcellini L, Stracuzzi M, Longoni E, Folgori L, Leone A, et al. Gastrointestinal Symptoms in Severe COVID-19 Children. Pediatr Infect Dis J. 2020;39(10):e317-e20.

45. Garazzino S, Montagnani C, Dona D, Meini A, Felici E, Vergine G, et al. Multicentre Italian study of SARS-CoV-2 infection in children and adolescents, preliminary data as at 10 April 2020. Euro Surveill. 2020;25(18).

46. de Ceano-Vivas M, Martin-Espin I, Del Rosal T, Bueno-Barriocanal M, Plata-Gallardo M, Ruiz-Dominguez JA, et al. SARS-CoV-2 infection in ambulatory and hospitalised Spanish children. Arch Dis Child. 2020;105(8):808-9.

47. Storch-de-Gracia P, Leoz-Gordillo I, Andina D, Flores P, Villalobos E, Escalada-Pellitero S, et al. Clinical spectrum and risk factors for complicated disease course in children admitted with SARS-CoV-2 infection. An Pediatr (Engl Ed). 2020;93(5):323-33.

48. Korkmaz MF, Ture E, Dorum BA, Kilic ZB. The Epidemiological and Clinical Characteristics of 81 Children with COVID-19 in a Pandemic Hospital in Turkey: an Observational Cohort Study. J Korean Med Sci. 2020;35(25):e236.

49. Yayla BCC, Aykac K, Ozsurekci Y, Ceyhan M. Characteristics and Management of Children With COVID-19 in a Tertiary Care Hospital in Turkey. Clin Pediatr (Phila). 2021;60(3):170-7.

50. Moraleda C, Serna-Pascual M, Soriano-Arandes A, Simo S, Epalza C, Santos M, et al. Multi-inflammatory Syndrome in Children Related to Severe Acute Respiratory Syndrome Coronavirus 2 (SARS-CoV-2) in Spain. Clin Infect Dis. 2021;72(9):e397-e401.

51. Pang J, Boshier FAT, Alders N, Dixon G, Breuer J. SARS-CoV-2 Polymorphisms and Multisystem Inflammatory Syndrome in Children. Pediatrics. $2020 ; 146(6)$.

52. Carbajal R, Lorrot M, Levy Y, Grimprel E, Lecarpentier T, Heritier S, et al. Multisystem inflammatory syndrome in children rose and fell with the first wave of the COVID-19 pandemic in France. Acta Paediatr. 2021;110(3):922-32.

53. Alkan G, Sert A, Oz SKT, Emiroglu M, Yilmaz R. Clinical features and outcome of MIS-C patients: an experience from Central Anatolia. Clin Rheumatol. 2021.

54. van der Zalm MM, Lishman J, Verhagen LM, Redfern A, Smit L, Barday M, et al. Clinical experience with SARS CoV-2 related illness in children hospital experience in Cape Town, South Africa. Clin Infect Dis. 2020.

55. Team CC-R. Coronavirus Disease 2019 in Children - United States, February 12-April 2, 2020. MMWR Morb Mortal Wkly Rep. 2020;69(14):422-6.

56. Chao JY, Derespina KR, Herold BC, Goldman DL, Aldrich M, Weingarten J, et al. Clinical Characteristics and Outcomes of Hospitalized and Critically III Children and Adolescents with Coronavirus Disease 2019 at a Tertiary Care Medical Center in New York City. J Pediatr. 2020;223:14-9 e2.

57. Desai A, Mills A, Delozier S, Cabrera Aviles C, Edwards A, Dirajlal-Fargo S, et al. Pediatric Patients with SARS-CoV-2 Infection: Clinical Characteristics in the United States from a Large Global Health Research Network. Cureus. 2020;12(9):e10413.

58. Fisler G, Izard SM, Shah S, Lewis D, Kainth MK, Hagmann SHF, et al. Characteristics and risk factors associated with critical illness in pediatric COVID-19. Ann Intensive Care. 2020;10(1):171.

59. Kainth MK, Goenka PK, Williamson KA, Fishbein JS, Subramony A, Barone S, et al. Early Experience of COVID-19 in a US Children's Hospital. Pediatrics. 2020;146(4).

60. Kalyanaraman Marcello R, Dolle J, Grami S, Adule R, Li Z, Tatem K, et al. Characteristics and outcomes of COVID-19 patients in New York City's public hospital system. PLoS One. 2020;15(12):e0243027.

61. Kim L, Whitaker M, O'Halloran A, Kambhampati A, Chai SJ, Reingold A, et al. Hospitalization Rates and Characteristics of Children Aged <18 Years Hospitalized with Laboratory-Confirmed COVID-19 - COVID-NET, 14 States, March 1-July 25, 2020. MMWR Morb Mortal Wkly Rep. 2020;69(32):1081-8.

62. Richardson S, Hirsch JS, Narasimhan M, Crawford JM, McGinn T, Davidson KW, et al. Presenting Characteristics, Comorbidities, and Outcomes Among 5700 Patients Hospitalized With COVID-19 in the New York City Area. JAMA. 2020;323(20):2052-9.

63. Verma S, Lumba R, Dapul HM, Gold-von Simson G, Phoon CK, Lighter JL, et al. Characteristics of Hospitalized Children With SARS-CoV-2 in the New York City Metropolitan Area. Hosp Pediatr. 2021;11(1):71-8.

64. Zachariah P, Johnson CL, Halabi KC, Ahn D, Sen Al, Fischer A, et al. Epidemiology, Clinical Features, and Disease Severity in Patients With Coronavirus Disease 2019 (COVID-19) in a Children's Hospital in New York City, New York. JAMA Pediatr. 2020;174(10):e202430. 
65. Graff K, Smith C, Silveira L, Jung S, Curran-Hays S, Jarjour J, et al. Risk Factors for Severe COVID-19 in Children. Pediatr Infect Dis J. 2021;40(4):e137-e45.

66. Preston LE, Chevinsky JR, Kompaniyets L, Lavery AM, Kimball A, Boehmer TK, et al. Characteristics and Disease Severity of US Children and Adolescents Diagnosed With COVID-19. JAMA Netw Open. 2021;4(4):e215298.

67. Abdel-Haq N, Asmar BI, Deza Leon MP, McGrath EJ, Arora HS, Cashen K, et al. SARS-CoV-2-associated multisystem inflammatory syndrome in children: clinical manifestations and the role of infliximab treatment. Eur J Pediatr. 2021;180(5):1581-91.

68. Capone CA, Subramony A, Sweberg T, Schneider J, Shah S, Rubin L, et al. Characteristics, Cardiac Involvement, and Outcomes of Multisystem Inflammatory Syndrome of Childhood Associated with severe acute respiratory syndrome coronavirus 2 Infection. J Pediatr. 2020;224:141-5.

69. Crawford RL, Bolin EH, Prodhan P, Renno MS, Knecht KR. Variable Presentation of COVID-19 in Pediatric Patients. Pediatr Infect Dis J. 2021;40(2):e88-e90.

70. Dufort EM, Koumans EH, Chow EJ, Rosenthal EM, Muse A, Rowlands J, et al. Multisystem Inflammatory Syndrome in Children in New York State. N Engl J Med. 2020;383(4):347-58.

71. Riollano-Cruz M, Akkoyun E, Briceno-Brito E, Kowalsky S, Reed J, Posada R, et al. Multisystem inflammatory syndrome in children related to COVID-19: A New York City experience. J Med Virol. 2021;93(1):424-33.

72. Rekhtman S, Tannenbaum R, Strunk A, Birabaharan M, Wright S, Garg A. Mucocutaneous disease and related clinical characteristics in hospitalized children and adolescents with COVID-19 and multisystem inflammatory syndrome in children. J Am Acad Dermatol. 2021;84(2):408-14.

73. Belay ED, Abrams J, Oster ME, Giovanni J, Pierce T, Meng L, et al. Trends in Geographic and Temporal Distribution of US Children With Multisystem Inflammatory Syndrome During the COVID-19 Pandemic. JAMA Pediatr. 2021.

74. Abrams JY, Oster ME, Godfred-Cato SE, Bryant B, Datta SD, Campbell AP, et al. Factors linked to severe outcomes in multisystem inflammatory syndrome in children (MIS-C) in the USA: a retrospective surveillance study. The Lancet Child \& Adolescent Health. 2021;5(5):323-31.

75. Araujo da Silva AR, Fonseca CGB, Miranda J, Travassos BV, Baião CR, Silva KD, et al. Respiratory and non-respiratory manifestations in children admitted with COVID-19 in Rio de Janeiro city, Brazil. medRxiv. 2021.

76. Hillesheim D, Tomasi YT, Figueiro TH, Paiva KM. Severe Acute Respiratory Syndrome due to COVID-19 among children and adolescents in Brazil: profile of deaths and hospital lethality as at Epidemiological Week 38, 2020. Epidemiol Serv Saude. 2020;29(5):e2020644.

77. Bolanos-Almeida CE, Espitia Segura OM. Clinical and Epidemiologic Analysis of COVID-19 Children Cases in Colombia PEDIACOVID. Pediatr Infect Dis J. 2021;40(1):e7-e11.

78. Cairoli H, Raiden S, Chiolo MJ, Di Lalla S, Ferrero F, Colaboradores. Patients assisted at the Department of Medicine of a pediatric hospital at the beginning of the COVID-19 pandemic in Buenos Aires, Argentina. Arch Argent Pediatr. 2020;118(6):418-26.

79. Sena GR, Lima TPF, Vidal SA, Duarte M, Bezerra PGM, Fonseca Lima EJ, et al. Clinical Characteristics and Mortality Profile of CoVID-19 Patients Aged less than 20 years Old in Pernambuco - Brazil. Am J Trop Med Hyg. 2021.

80. Torres JP, Izquierdo G, Acuna M, Pavez D, Reyes F, Fritis A, et al. Multisystem inflammatory syndrome in children (MIS-C): Report of the clinical and epidemiological characteristics of cases in Santiago de Chile during the SARS-CoV-2 pandemic. Int J Infect Dis. 2020;100:75-81.

81. Clark BC, Sanchez-de-Toledo J, Bautista-Rodriguez C, Choueiter N, Lara D, Kang H, et al. Cardiac Abnormalities Seen in Pediatric Patients During the SARS-CoV2 Pandemic: An International Experience. J Am Heart Assoc. 2020;9(21):e018007.

82. Bain R, Cosgriff R, Zampoli M, Elbert A, Burgel PR, Carr SB, et al. Clinical characteristics of SARS-CoV-2 infection in children with cystic fibrosis: An international observational study. J Cyst Fibros. 2021;20(1):25-30.

83. Simpson M, Collins C, Nash DB, Panesar LE, Oster ME. Coronavirus Disease 2019 Infection in Children with Pre-Existing Heart Disease. J Pediatr. 2020;227:302-7 e2.

84. Esmaeeli H, Ghaderian M, Zanjani KS, Ghalibafan SF, Mahdizadeh M, Aelami MH. COVID-19 in Children with Congenital Heart Diseases: A Multicenter Case Series from Iran. Case Rep Pediatr. 2021;2021:6690695.

85. Bisogno G, Provenzi M, Zama D, Tondo A, Meazza C, Colombini A, et al. Clinical Characteristics and Outcome of Severe Acute Respiratory Syndrome Coronavirus 2 Infection in Italian Pediatric Oncology Patients: A Study From the Infectious Diseases Working Group of the Associazione Italiana di Oncologia e Ematologia Pediatrica. J Pediatric Infect Dis Soc. 2020;9(5):530-4. 
86. de Rojas T, Perez-Martinez A, Cela E, Baragano M, Galan V, Mata C, et al. COVID-19 infection in children and adolescents with cancer in Madrid. Pediatr Blood Cancer. 2020;67(7):e28397.

87. Ebeid FSE, Ragab IA, Elsherif NHK, Makkeyah S, Mostafa S, Eltonbary K, et al. COVID-19 in Children With Cancer: A Single Low-Middle Income Center Experience. J Pediatr Hematol Oncol. 2020.

88. Ferrari A, Zecca M, Rizzari C, Porta F, Provenzi M, Marinoni M, et al. Children with cancer in the time of COVID-19: An 8-week report from the six pediatric onco-hematology centers in Lombardia, Italy. Pediatr Blood Cancer. 2020;67(8):e28410.

89. Gampel B, Troullioud Lucas AG, Broglie L, Gartrell-Corrado RD, Lee MT, Levine J, et al. COVID-19 disease in New York City pediatric hematology and oncology patients. Pediatr Blood Cancer. 2020;67(9):e28420.

90. Millen GC, Arnold R, Cazier JB, Curley H, Feltbower RG, Gamble A, et al. Severity of COVID-19 in children with cancer: Report from the United Kingdom Paediatric Coronavirus Cancer Monitoring Project. Br J Cancer. 2021;124(4):754-9.

91. Palomo-Colli MA, Fuentes-Lugo AD, Cobo-Ovando SR, Juarez-Villegas L. COVID-19 in Children and Adolescents With Cancer From a Single Center in Mexico City. J Pediatr Hematol Oncol. 2020.

92. Radhakrishnan V, Ovett J, Rajendran A, Kolluru S, Pai V, Gnanaguru V, et al. COVID19 in children with cancer in low- and middle-income countries: Experience from a cancer center in Chennai, India. Pediatr Hematol Oncol. 2021;38(2):161-7.

93. Sánchez-Jara B, Torres-Jiménez AR, Del Campo-Martinez MdIA, Ortíz-Torres MG, García-Soto A, Loza-Santiaguillo PdR, et al. Clinical characteristics and evolution of pediatric patients with acute leukemia and SARS-COV2 virus infection in a third level hospital in Mexico. Pediatric Hematology Oncology Journal. 2021;6(1):42-8.

94. Madhusoodhan PP, Pierro J, Musante J, Kothari P, Gampel B, Appel B, et al. Characterization of COVID-19 disease in pediatric oncology patients: The New York-New Jersey regional experience. Pediatr Blood Cancer. 2021;68(3):e28843.

95. Kebudi R, Kurucu N, Tugcu D, Hacisalihoglu S, Fisgin T, Ocak S, et al. COVID-19 infection in children with cancer and stem cell transplant recipients in Turkey: A nationwide study. Pediatr Blood Cancer. 2021;68(6):e28915.

96. Lima ALMdA, Borborema MdCD, Matos APR, Oliveira KMMd, Mello MJG, Lins MM. COVID-19 cohort on children with cancer: delay in treatment and increased frequency of deaths. Revista Brasileira de Saúde Materno Infantil. 2021;21(suppl 1):299-304.

97. Fonseca EV, Pardo CA, Linares A, Lopez JF, Camacho G, Aponte NH, et al. Clinical Characteristics and Outcomes of a Cohort of Pediatric Oncohematologic Patients With COVID-19 Infection in the City of Bogota, Colombia. Pediatr Infect Dis J. 2021;40(6):499-502.

98. Vicent MG, Martinez AP, Trabazo Del Castillo M, Molina B, Sisini L, Moron-Cazalilla G, et al. COVID-19 in pediatric hematopoietic stem cell transplantation: The experience of Spanish Group of Transplant (GETMON/GETH). Pediatr Blood Cancer. 2020;67(9):e28514.

99. Arlet J-B, de Luna G, Khimoud D, Odièvre M-H, de Montalembert M, Joseph L, et al. Prognosis of patients with sickle cell disease and COVID-19: a French experience. The Lancet Haematology. 2020;7(9):e632-e4.

100. Telfer P, De la Fuente J, Sohal M, Brown R, Eleftheriou P, Roy N, et al. Real-time national survey of COVID-19 in hemoglobinopathy and rare inherited anemia patients. Haematologica. 2020;105(11):2651-4.

101. El Dannan H, Al Hassani M, Ramsi M. Clinical course of COVID-19 among immunocompromised children: a clinical case series. BMJ Case Rep. $2020 ; 13(10)$.

102. Perez-Martinez A, Guerra-Garcia P, Melgosa M, Frauca E, Fernandez-Camblor C, Remesal A, et al. Clinical outcome of SARS-CoV-2 infection in immunosuppressed children in Spain. Eur J Pediatr. 2021;180(3):967-71.

103. Melgosa M, Madrid A, Alvarez O, Lumbreras J, Nieto F, Parada E, et al. SARS-CoV-2 infection in Spanish children with chronic kidney pathologies. Pediatr Nephrol. 2020;35(8):1521-4.

104. Marlais M, Wlodkowski T, Al-Akash S, Ananin P, Bandi VK, Baudouin V, et al. COVID-19 in children treated with immunosuppressive medication for kidney diseases. Arch Dis Child. 2020.

105. Villacis-Nunez DS, Rostad CA, Rouster-Stevens K, Khosroshahi A, Chandrakasan S, Prahalad S. Outcomes of COVID-19 in a cohort of pediatric patients with Rheumatic Diseases. Paediatric Rheumatology BMC. 2021;In Review.

106. Kehar M, Ebel NH, Ng VL, Baquero JER, Leung DH, Slowik V, et al. Severe Acute Respiratory Syndrome Coronavirus-2 Infection in Children With Liver Transplant and Native Liver Disease: An International Observational Registry Study. J Pediatr Gastroenterol Nutr. 2021;72(6):807-14. 


\section{Supplementary Files}

This is a list of supplementary files associated with this preprint. Click to download.

- Harwood.SupplementaryMaterialmetaanalysissystematicreview.pdf 